\title{
Electrodeposition of ZnNi Alloys from Choline Chloride/Ethylene Glycol Deep Eutectic Solvent and Pure Ethylene Glycol for Corrosion Protection
}

\author{
Published as part of The Journal of Physical Chemistry virtual special issue "Deep Eutectic Solvents".
}

R. Bernasconi, G. Panzeri, G. Firtin, B. Kahyaoglu, L. Nobili, and L. Magagnin*

Cite This: J. Phys. Chem. B 2020, 124, 10739-10751

Read Online

ABSTRACT: The present work follows the trend to develop nonaqueous electrolytes for the deposition of corrosion resistant $\mathrm{ZnNi}$ alloys. It investigates the use of the choline chloride/ethylene glycol (1:2 molar ratio) eutectic mixture and of pure ethylene glycol as solvents for $\mathrm{ZnNi}$ electroplating. The electrochemical behavior of $\mathrm{Zn}$ and $\mathrm{Ni}$ is investigated via cyclic voltammetry, and potentiostatic $\mathrm{ZnNi}$ deposition is performed. $\mathrm{Ni}$ content is found to be precisely tunable in the $10-20 \%$ wt range, which presents the highest industrial interest for corrosion protection. $\mathrm{ZnNi}$ coatings obtained are characterized from the morphological and phase composition point of view. Evidence of the formation of a metastable $\gamma \mathrm{ZnNi}$ phase is observed for both choline chloride/ ethylene glycol and pure ethylene glycol. Finally, potentiodynamic corrosion tests are performed to assess their corrosion properties.

\section{INTRODUCTION}

Electrodeposited zinc-nickel alloys are widely employed in surface finishing as corrosion protection coatings on steel substrates. ${ }^{1,2}$ Among the possible film compositions, zinc-rich stoichiometry is one of the most exploited due to the low corrosion potential of the $\gamma$-phase $(9-15 \%$ wt $\mathrm{Ni}$ ) that makes it an ideal sacrificial layer in case the substrate is exposed to the environment. ${ }^{2}$ Aside from being largely used at the industrial level, the scientific community investigated the $\mathrm{ZnNi}$ system also because it undergoes anomalous co-deposition, ${ }^{3}$ where the less noble element is preferentially deposited under the majority of plating conditions regardless of the relative ionic concentration in the plating bath. ${ }^{4,5}$ This poses a limitation, since the corrosion properties of the coating are difficult to be tailored if relying on aqueous systems, due to the poor control on composition. The increase in nickel content would indeed lower the driving force of the galvanic couple but would increase the lifetime of the coating itself due to the lower corrosion rate. ${ }^{6}$

For these reasons, organic solutions were considered as a possible substitute for the traditional aqueous ones, showing higher control on the alloy composition. ${ }^{7-11}$ In the framework of nonaqueous solutions, choline chloride based deep eutectic solvents (DESs) $)^{12}$ are one of the most investigated systems

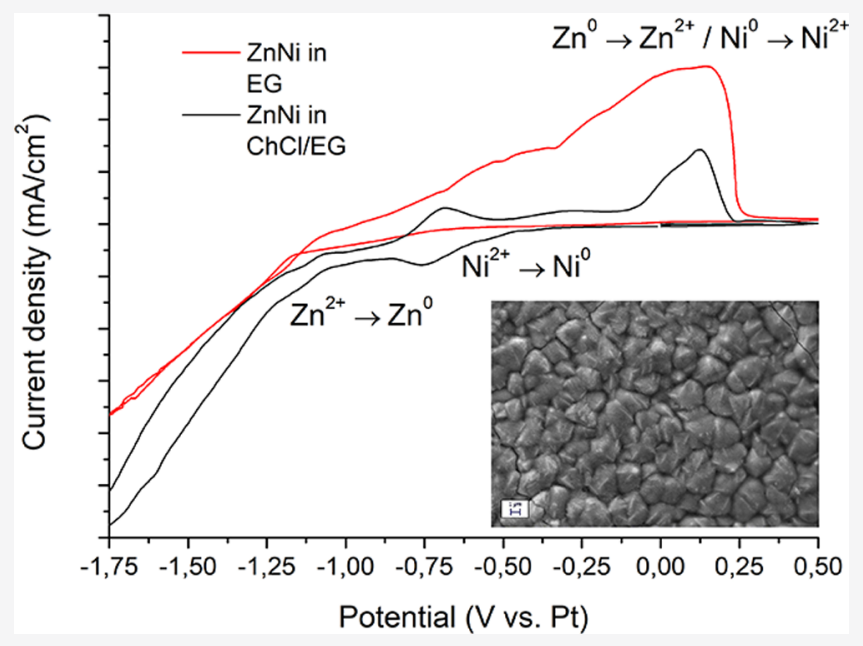

alternatively to traditional plating, ${ }^{13-15}$ counting several efforts toward making them appealing for industrial applications. ${ }^{16-24}$ Their relative low cost, sustainability, and physicochemical properties have indeed attracted the attention of researchers aiming to improve the coating properties and/or the process efficiency with respect to water based ones, as in the case of $\mathrm{Zn}^{25-31}$ and $\mathrm{Zn}$ based alloys. ${ }^{32-38}$ The wider electrochemical window of these DESs (2.1-2.2 V for choline chloride/urea 1:2 mixtures; $1.7-2.1 \mathrm{~V}$ for choline chloride/ethylene glycol 1:2 mixtures $^{39}$ ) makes them suitable for the plating of metals with low reduction potential by limiting the onset of secondary reactions such as hydrogen evolution, affecting both coating and substrate properties. $^{40-42}$ In turn, DESs are also characterized by significant drawbacks. In particular, their comparatively high viscosity reduces mass transfer of electro-

Received: May 27, 2020

Revised: October 30, 2020

Published: November 11, 2020 
a)

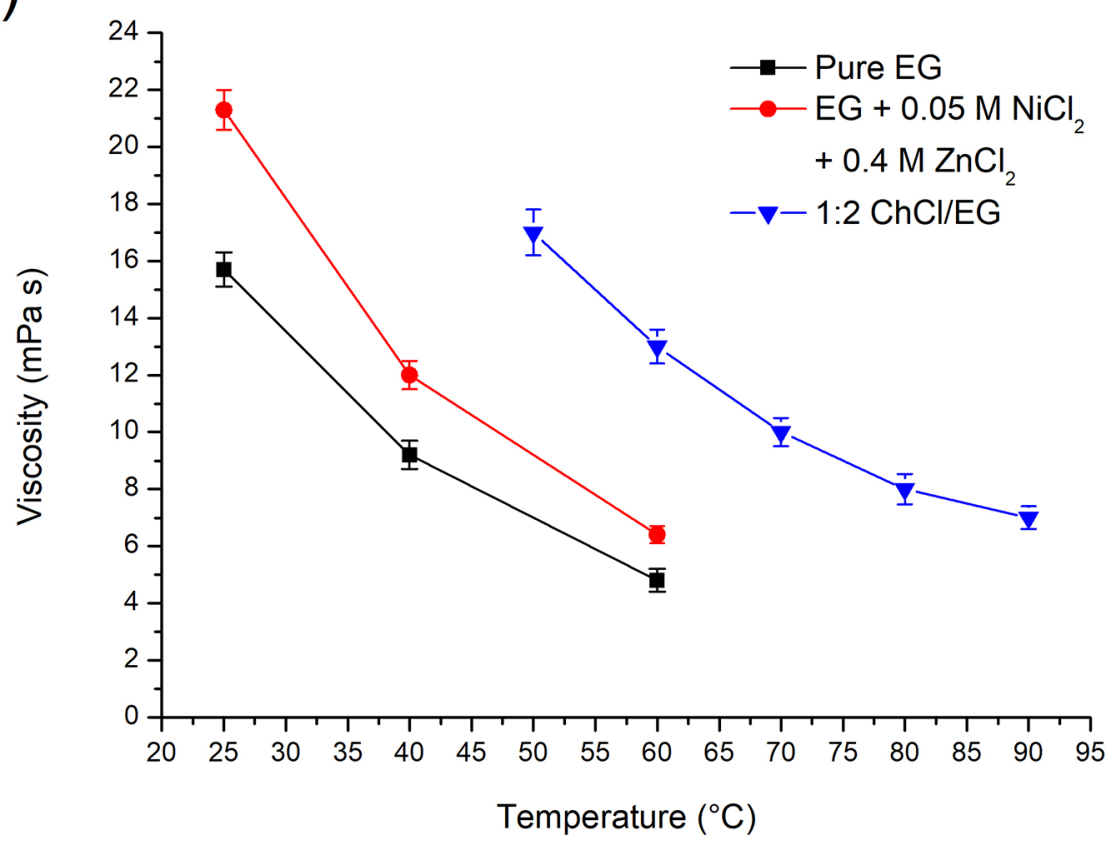

b)

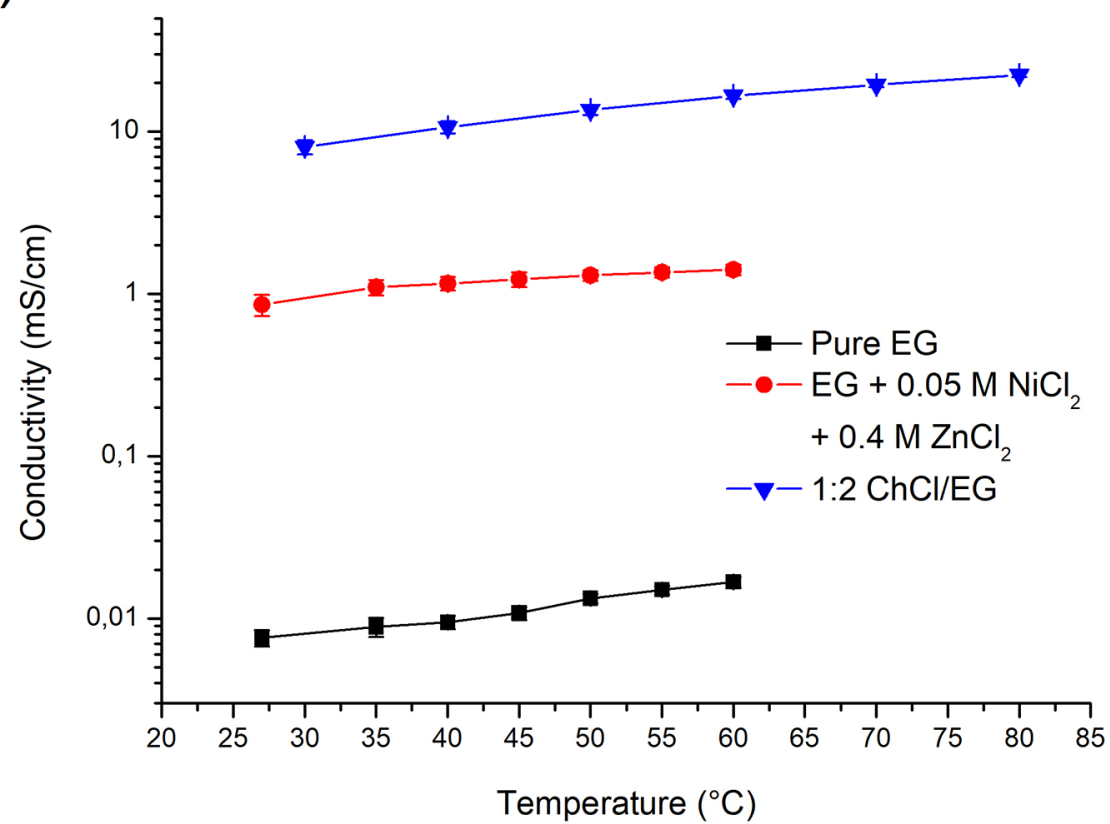

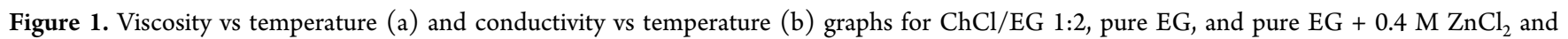
$0.05 \mathrm{M} \mathrm{NiCl}_{2}$.

active species. ${ }^{43}$ Moreover, the purity of the DES components is harder to control with respect to aqueous solutions.

The electrodeposition of $\mathrm{Zn}-\mathrm{Ni}$ alloys, in the framework of DES, has been investigated mostly from the choline chloride/ urea system (1ChCl:2U). ${ }^{7,9-11}$ The study of Yang et al. ${ }^{7}$ focused on the synthesis and characterization of Ni-rich alloys (50-100\% wt Ni). The zinc content progressively increased with the cathodic potential applied, associated with the formation of cracks in the film. Fashu et al. ${ }^{9,10}$ further examined this system by exploring the effect of the different experimental parameters and additives (EDTA and $\mathrm{NH}_{4} \mathrm{Cl}$ ) aiming at the formation of a smooth and crack-free Ni-rich film. Conversely, Zn-rich coatings were obtained by tailoring the water content in the $1 \mathrm{ChCl}: 2 \mathrm{U}$ solution, shifting the compositional window from $50-100 \%$ wt to $5-40 \%$ wt of nickel. ${ }^{11}$ The corrosion properties of the coating were investigated at different compositions, showing higher corrosion potentials and lower corrosion currents progressively increasing the nickel content. Ethylene glycol based DES (1ChCl:2EG), on the other hand, was first investigated for the $\mathrm{ZnNi}$ alloy electrodeposition by Pereira et al., ${ }^{8}$ focusing on the effect of amines on the morphology of zinc-rich films having 5-7\% wt Ni. The system was allowed to cover a broader 
a)

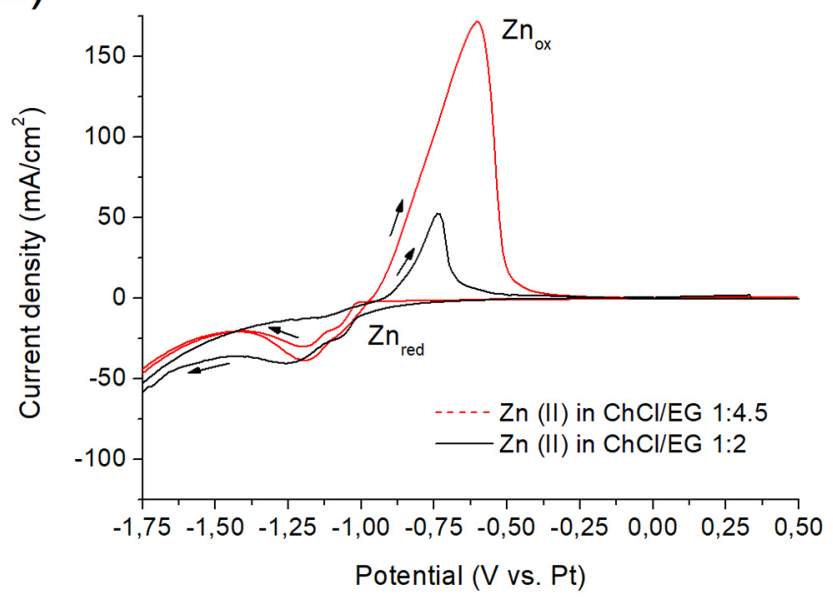

c)

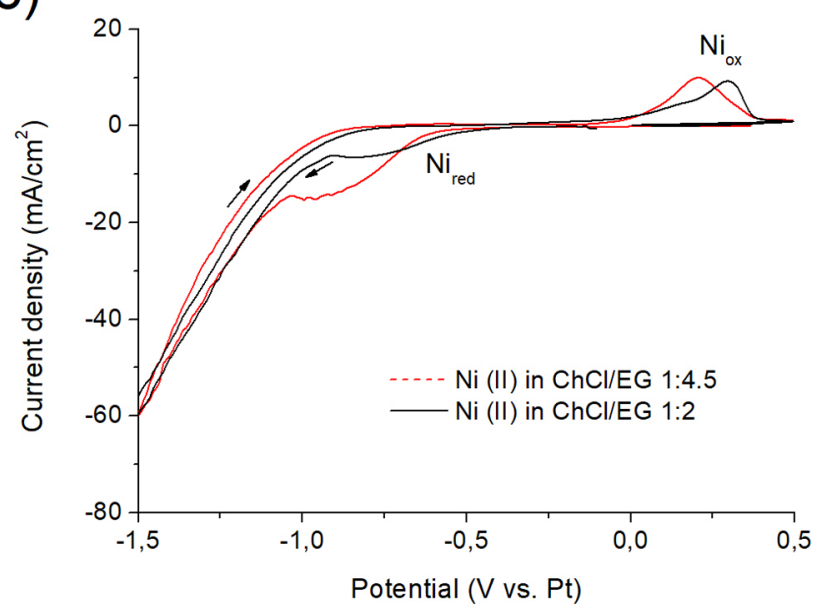

e)

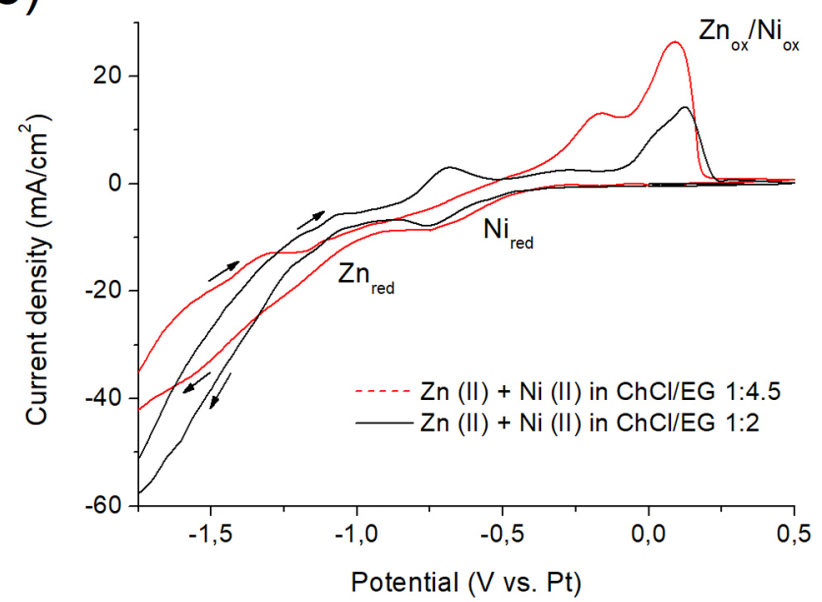

b)

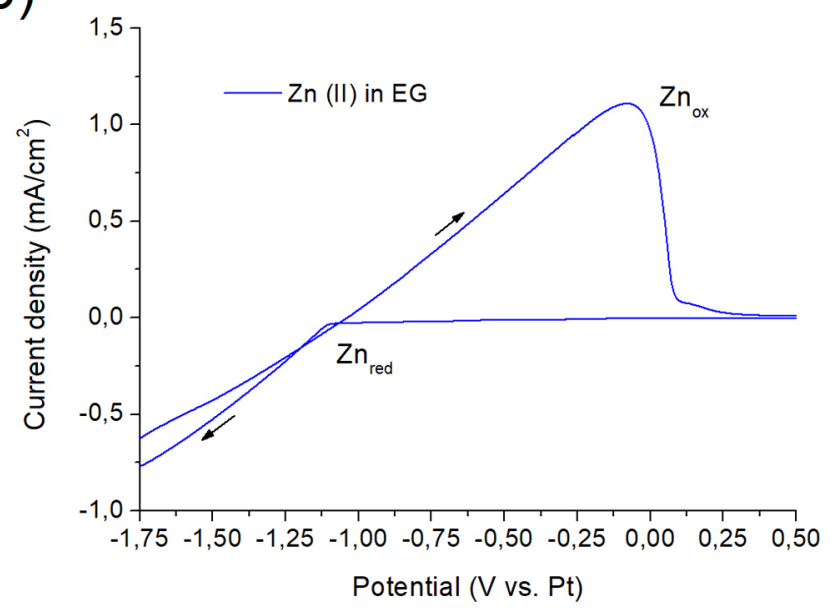

d)

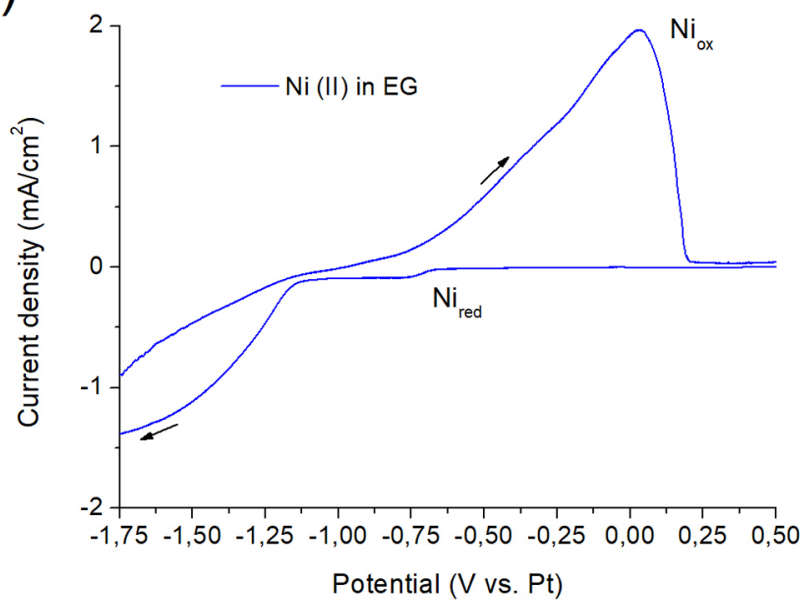

f)

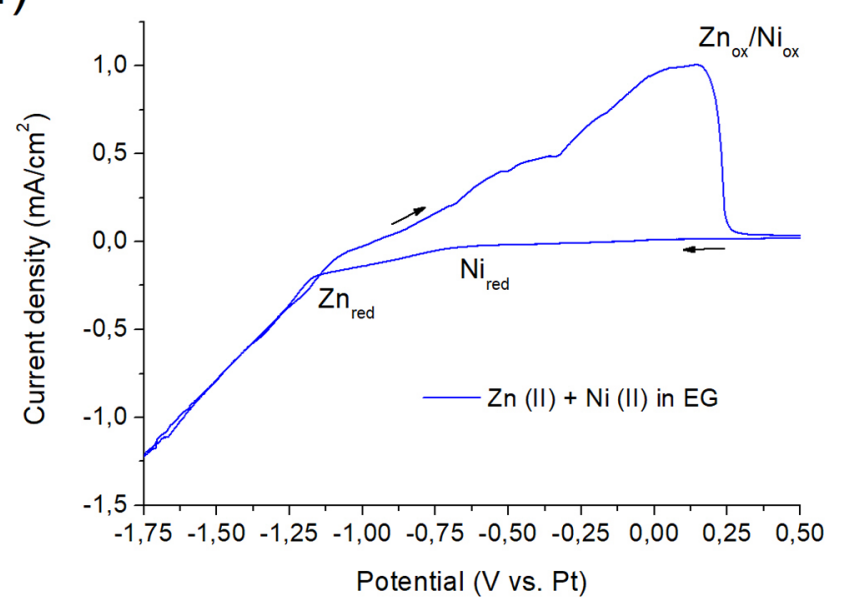

Figure 2. Cyclic voltammetries for different electrolytes: $\mathrm{ChCl} / \mathrm{EG}+\mathrm{Zn}(\mathrm{a}), \mathrm{EG}+\mathrm{Zn}(\mathrm{b}), \mathrm{ChCl} / \mathrm{EG}+\mathrm{Ni}(\mathrm{c}), \mathrm{EG}+\mathrm{Ni}(\mathrm{d}), \mathrm{ChCl} / \mathrm{EG}+\mathrm{Zn}+\mathrm{Ni}$ (e), EG $+\mathrm{Zn}+\mathrm{Ni}(\mathrm{f})$.

compositional window $\left(3-80 \%\right.$ wt Ni), ${ }^{44}$ at a fixed electrolyte composition, with respect to the urea based one.

Literature studies also reported the possibility to use bare ethylene glycol (EG) as a solvent, avoiding or limiting the chloride concentration in the bath, ${ }^{45-52}$ showing beneficial effects on coating properties ${ }^{53}$ and affecting the electrochemical behavior of the cationic species. ${ }^{54}$ Although the chloride ions coming from choline chloride $(\mathrm{ChCl})$ are responsible for the relatively high conductivity value of these electrolytes, they may affect the electrodeposit because of their intrinsic aggressivity, especially in the case of low nobility metals or alloys, such as zinc-rich ones.

In this work, we studied the effect of choline chloride concentration on the co-electrodeposition of $\mathrm{ZnNi}$ alloys with 
the focus on how anomalous deposition is affected. The wellknown deep eutectic solvent choline chloride/ethylene glycol ( $\mathrm{ChCh} / \mathrm{EG}$ in 1:2 molar ratio) is compared to a plating bath relying only on ethylene glycol as solvent. Electrolytes' physical and electrochemical properties are investigated, and potentiostatic deposition on iron substrates is performed. Resulting $\mathrm{ZnNi}$ coatings are then characterized from the morphological point of view, and their phase composition is determined. Finally, corrosion protection performances of the $\mathrm{ZnNi}$ layers obtained from $\mathrm{ChCl} / \mathrm{EG} 1: 2$ and $\mathrm{EG}$ are determined.

\section{METHODS}

Anhydrous ethylene glycol $\left(\mathrm{C}_{2} \mathrm{H}_{6} \mathrm{O}_{2} ;\right.$ Sigma-Aldrich; purity 99.8\%; water content $\leq 0.003 \%)$, choline chloride $\left(\mathrm{C}_{5} \mathrm{H}_{14} \mathrm{ClNO}\right.$; Sigma-Aldrich; purity $\geq 99 \%$; water content $\leq 0.5 \%)$, zinc(II) chloride $\left(\mathrm{ZnCl}_{2} ;\right.$ Sigma-Aldrich; purity $\geq 98 \%$ ), and nickel(II) chloride hexahydrate $\left(\mathrm{NiCl}_{2} \cdot 6 \mathrm{H}_{2} \mathrm{O}\right.$; Sigma-Aldrich; purity $\geq 98 \%$ ) were used as received. Three base solvents were employed: a $\mathrm{ChCl} / \mathrm{EG} \mathrm{1:2} \mathrm{molar} \mathrm{ratio}$ mixture, a $\mathrm{ChCl} / \mathrm{EG}$ 1:4.5 molar ratio mixture, and pure EG. $\mathrm{Ni}$ and $\mathrm{Zn}$ salts were dissolved in these three solvents according to the quantities detailed in the results part, and the resulting electrolytes were used to perform $\mathrm{ZnNi}$ deposition. Solutions were maintained at the usage temperature $\left(70{ }^{\circ} \mathrm{C}\right.$ for $\mathrm{ChCl} / \mathrm{EG} \mathrm{1:2}$ and $\mathrm{ChCl} / \mathrm{EG} 1: 4.5$ based baths; $60^{\circ} \mathrm{C}$ for pure EG based baths) during solution preparation, electrochemical characterization, and electrodeposition using a thermal jacket controlled by a thermocouple. Where specified, samples were annealed at $400{ }^{\circ} \mathrm{C}$ for $1 \mathrm{~h}$ in an inert atmosphere $\left(\mathrm{N}_{2}\right)$. The electrochemical characterization was performed in a standard three-electrode cell setup, employing an AMEL2550 potentiostat/galvanostat. Cyclic voltammetry $(\mathrm{CV})$ was done using a platinum wire as working, counter, and reference electrodes. A $20 \mathrm{mV} / \mathrm{s}$ scan rate was employed, and no stirring was applied. An AMEL2550 potentiostat/galvanostat was used also to perform potentiostatic deposition tests. In this case, however, mild steel plates were used as working electrodes, while a platinum wire was used as reference and counter electrode. The steel surface was cleaned in acetone and etched in a $20 \%$ wt $\mathrm{HCl}$ solution to remove surface oxides. Cathodic efficiencies in the $60-70 \%$ range were observed for $\mathrm{Ni}$ contents ranging from 16 to $18 \%$ wt. Potentiodynamic polarization tests were done in a $5 \%$ wt $\mathrm{NaCl}$ aqueous solution. A $1 \mathrm{mV} / \mathrm{s}$ scan rate was employed, and the solution was not stirred. SEM was carried out employing a Zeiss EVO $50 \mathrm{EP}$ setup, equipped with an energy dispersive spectroscopy (EDS) module (Oxford instruments INCA). A Philips PW1830 $\left(K_{\alpha 1 \mathrm{Cu}}=1.54058 \AA\right)$ setup was employed to perform $\mathrm{XRD}$. Film composition was determined by X-ray fluorescence spectroscopy (XRF), using a Fischerscope X-ray XAN. Conductivity was measured using a AMEL model 2131 conductivity meter, while viscosity was evaluated using a Haake Viscotester VT5R rotational viscometer. Electrolyte water content was determined via Karl Fischer titration with a Metrohm $870 \mathrm{KF}$ Titrino Plus. Both deposition experiments and characterization tests were repeated at least twice to evaluate repeatability. No significant deviations from the data presented were observed.

\section{RESULTS AND DISCUSSION}

Electrolyte Water Content. Water content is an important parameter in the case of electrodeposition from
Table 1. $E_{\text {on }}$ Values for the Voltammetries Depicted in Figure 2

\begin{tabular}{lccccc} 
& $\begin{array}{c}E_{\text {on }} \\
\mathrm{Zn}_{\text {red }} \text { in } \\
\text { solvent }\end{array}$ & $\begin{array}{c}E_{\text {on }} \\
\mathrm{Ni}_{\text {red }} \text { in } \\
\mathrm{Ni} \text { bath }\end{array}$ & $\begin{array}{c}E_{\text {on }} \mathrm{Zn}_{\text {red }} \\
\text { in } \mathrm{ZnNi} \\
\text { bath }\end{array}$ & $\begin{array}{c}E_{\text {on }} \mathrm{Ni}_{\text {red }} \\
\text { in } \mathrm{ZnNi} \\
\text { bath }\end{array}$ & $\begin{array}{c}\Delta E_{\text {on }} \\
\mathrm{Zn}_{\text {red }} / \mathrm{Ni}_{\text {red }} \\
\text { in } \mathrm{ZnNi}\end{array}$ \\
$\mathrm{ChCl/EG} \mathrm{1:2}$ & -1.01 & -0.52 & -1.17 & -0.5 & 0.67 \\
$\mathrm{ChCl}$ EG 1:4.5 & -1.02 & -0.62 & -1.07 & -0.55 & 0.52 \\
pure EG & -1.11 & -0.67 & -1.17 & -0.68 & 0.49 \\
\hline
\end{tabular}

nonaqueous solutions, since it considerably influences the electrochemical behavior of the metallic ions present in the bath, the potential window of the electrolyte, and its conductivity/viscosity. In the case of deep eutectic solvents, water contamination can be beneficial or detrimental according to the metal plated. For example, Ni electrodeposition in 1:2 choline chloride-urea is negatively affected by water concentrations higher than $4.5 \%$ wt. Under these conditions, as demonstrated by Lukaczynska et al., ${ }^{55}$ the $\mathrm{Ni}$ coating incorporates degradation products from the electrolyte. On the other side, $\mathrm{Cu}$ deposition in 1:2 $\mathrm{ChCl} / \mathrm{EG}$ is positively affected by water. Valverde et al. ${ }^{56}$ demonstrated that water increases deposition rates and electrolyte conductivity.

In front of these considerations, the water concentration of the electrolytes employed in the present work was estimated. By considering only the water content declared by the manufacturer for the solvents employed ( $\mathrm{ChCl} / \mathrm{EG}$ and pure $\mathrm{EG})$, water concentration was limited to less than $0.003 \%$ wt in the case of pure EG, $0.169 \%$ wt for $\mathrm{ChCl} / \mathrm{EG} 1: 4.5$, and 0.266 wt $\%$ in the case of $\mathrm{ChCl} / \mathrm{EG} \mathrm{1:2.} \mathrm{However,} \mathrm{additional} \mathrm{water}$ was incorporated from the nickel salt employed, which was hydrated. To quantify water content, Karl Fischer titration was performed on the electrolytes with the highest expected water content. These are the ones containing the highest concentration of nickel chloride: $\mathrm{ChCl} / \mathrm{EG}+0.2 \mathrm{M} \mathrm{ZnCl}_{2}+$ $0.13 \mathrm{M} \mathrm{NiCl}_{2}$ and $\mathrm{EG}+0.2 \mathrm{M} \mathrm{ZnCl}_{2}+0.15 \mathrm{M} \mathrm{NiCl}_{2}$. The results obtained evidenced a water content equal to $1.54 \pm$ $0.02 \%$ wt for the $\mathrm{ChCl} / \mathrm{EG}$ based electrolytes and to $1.42 \pm$ $0.02 \%$ wt in the case of the electrolyte based on EG.

It is fundamental to emphasize, however, that the electrolytes change their water content with time due to atmospheric moisture absorption. Indeed, both $\mathrm{ChCl}$ and $\mathrm{EG}$ are hygroscopic. This contribution is hard to quantify, as it depends on the temperature of the solution, the relative humidity of the air and the exposure time to humidity itself. It has been reported in the literature ${ }^{57}$ that maintaining the solution at high temperature significantly limits water uptake. As an example, $\mathrm{ChCl} / \mathrm{EG}$ at room temperature rapidly incorporates water and reaches a content equal to $40 \% \mathrm{wt}$ after 60 days. If the same solution is heated at $80^{\circ} \mathrm{C}$, the water content decreases to $1.5 \% \mathrm{wt}$ after 18 days.

Electrolyte Physical Properties. The general physical behavior of $\mathrm{ChCl} / \mathrm{EG} \mathrm{1:2}$ based electrolytes is relatively wellknown. ${ }^{58}$ The same is true for non-eutectic mixtures of $\mathrm{ChCl} /$ EG (like the 1:4.5 molar ratio ${ }^{59}$ ) but not for pure EG based electrolytes, since they have been developed only in the past few years. Therefore, it is fundamental to provide a clear characterization of their physical properties, in particular viscosity and conductivity. A very high viscosity may constitute an issue for electrodeposition, since highly viscous fluids are typically characterized by reduced ionic mobility. At the same time, a low conductivity may represent a serious obstacle for successful metal deposition, with reduced power efficiencies and difficulties in the formation of uniform layers. ${ }^{60,61}$ 
a)

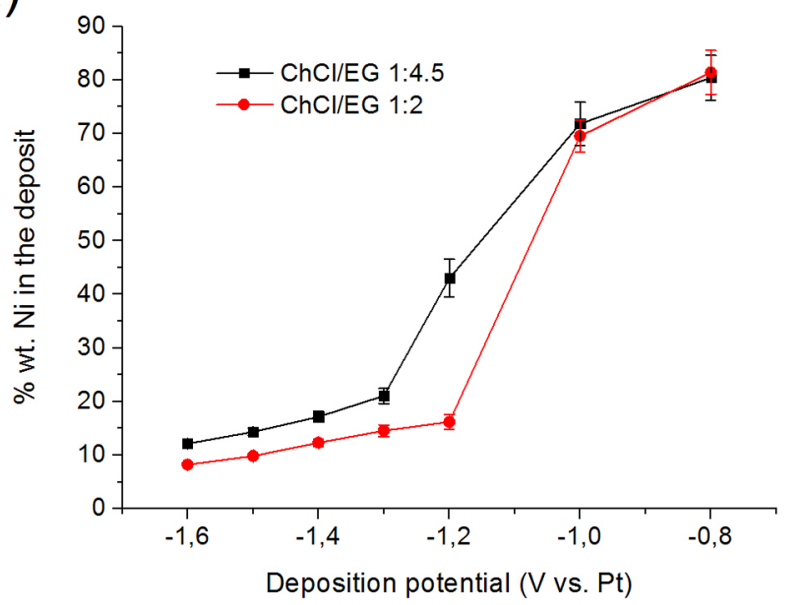

c)

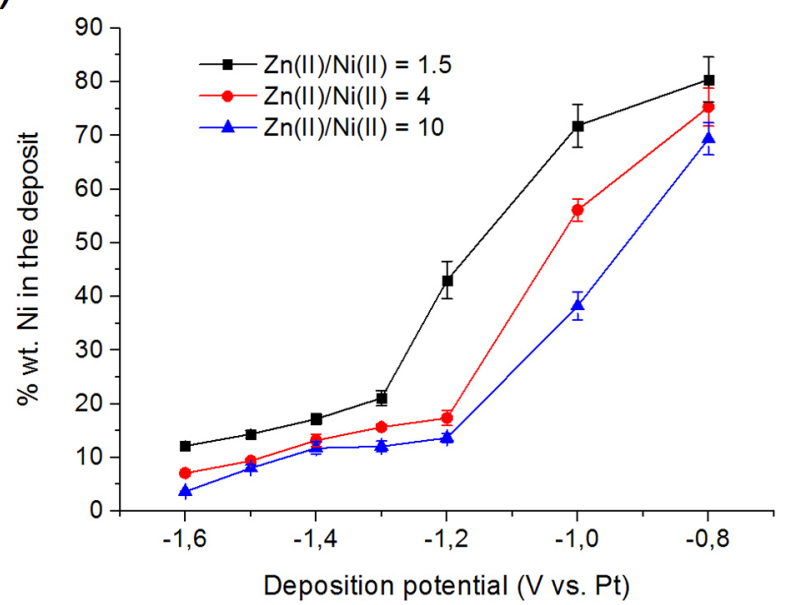

e)

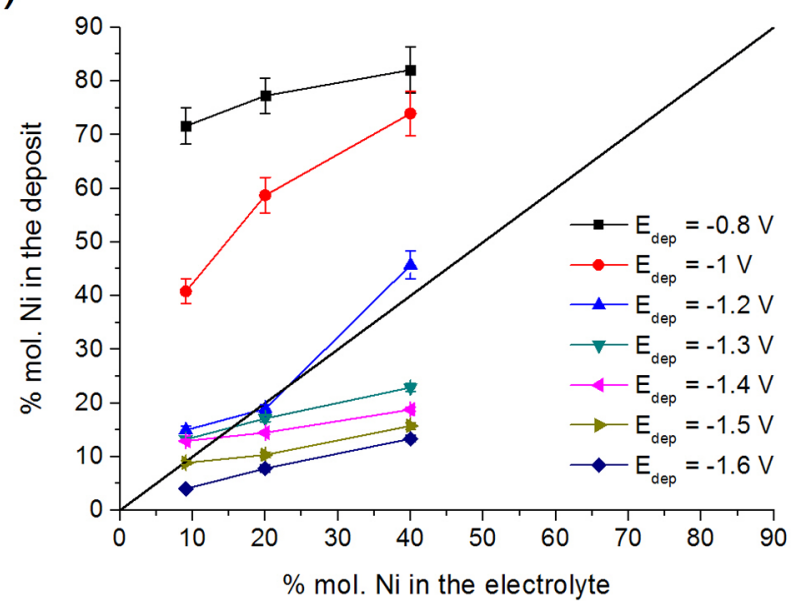

b)

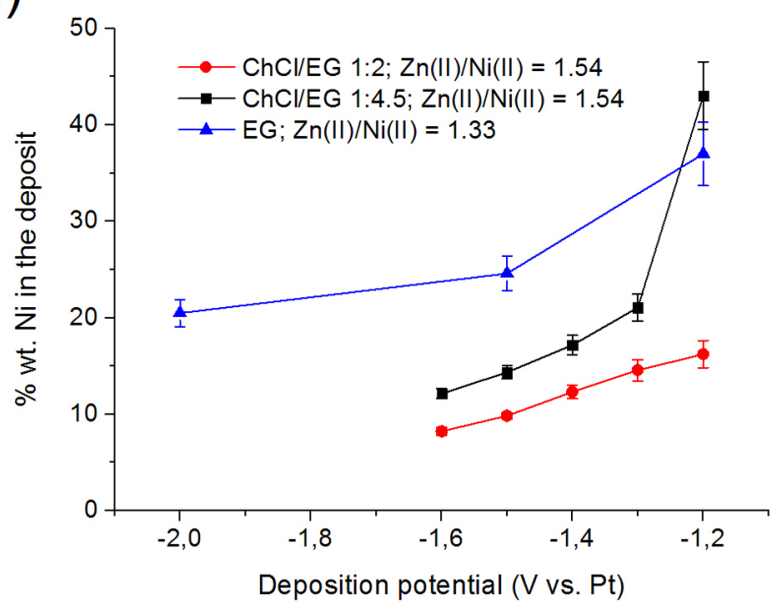

d)

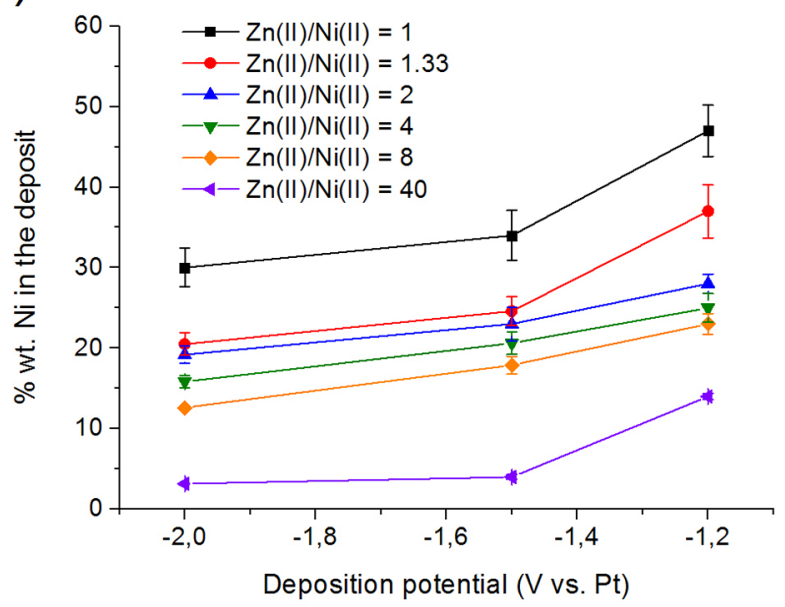

f)

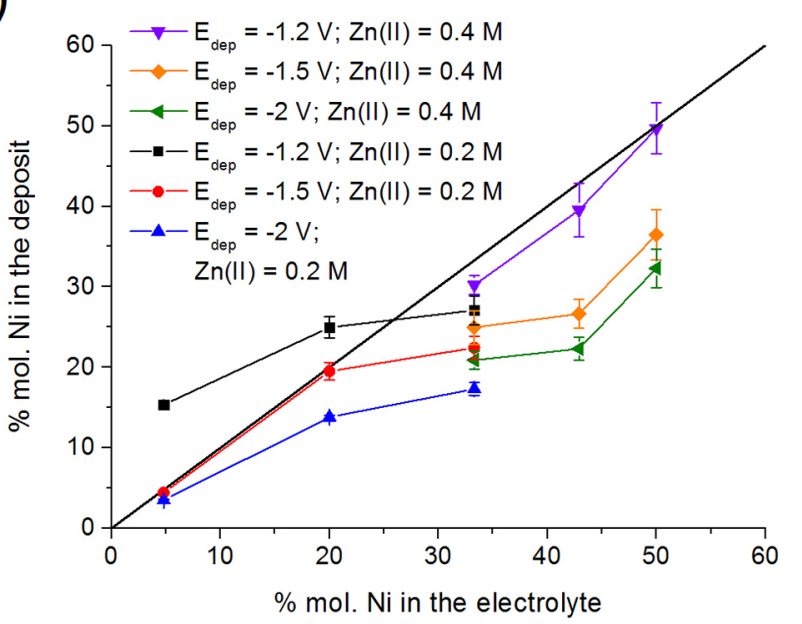

Figure 3. Effect of $\mathrm{ChCl} / \mathrm{EG}$ ratio variation on $\mathrm{Ni}$ content as a function of deposition potential (a and $\mathrm{b}$ ); effect of $\mathrm{Zn}$ (II)/ $\mathrm{Ni}$ (II) ratio variation on $\mathrm{Ni}$ content as a function of deposition potential in $\mathrm{ChCl} / \mathrm{EG}$ (c); effect of $\mathrm{Zn}(\mathrm{II}) / \mathrm{Ni}$ (II) ratio variation on $\mathrm{Ni}$ content as a function of deposition potential in EG (d); $\mathrm{Ni} \%$ mol. in the deposit vs $\mathrm{Ni} \%$ mol. in the bath for $\mathrm{ChCl} / \mathrm{EG}$ (e); $\mathrm{Ni} \%$ mol. in the deposit vs $\mathrm{Ni} \% \mathrm{~mol}$. in the bath for $\mathrm{EG}$ (f).

$\mathrm{ChCl} / \mathrm{EG}$ 1:2 and EG dynamic viscosity was determined, and it is plotted in Figure 1a. Coherently with state-of-the-art measurements, ${ }^{58} \mathrm{ChCl} / \mathrm{EG} \quad 1: 2$ was characterized by a relatively high viscosity, which reached values suitable for electrodeposition only at rather high temperatures. This is a consequence of the ionic nature of the fluid and of the dimension of the choline anion, which is quite large and characterized by low mobility. As a result of its high viscosity, electrodeposition from $\mathrm{ChCl} / \mathrm{EG} \mathrm{1:2}$ is normally performed in the $70-80{ }^{\circ} \mathrm{C}$ temperature range. 
a)

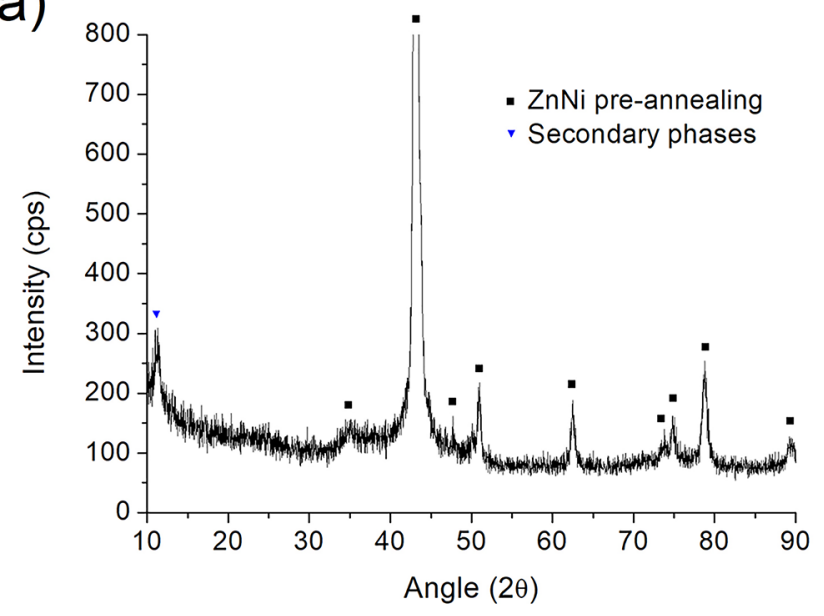

c)

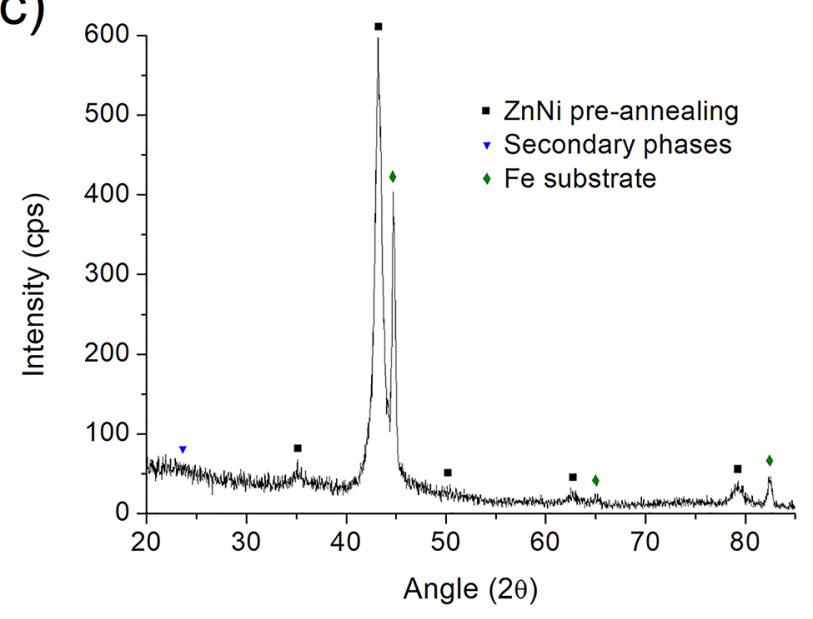

b)

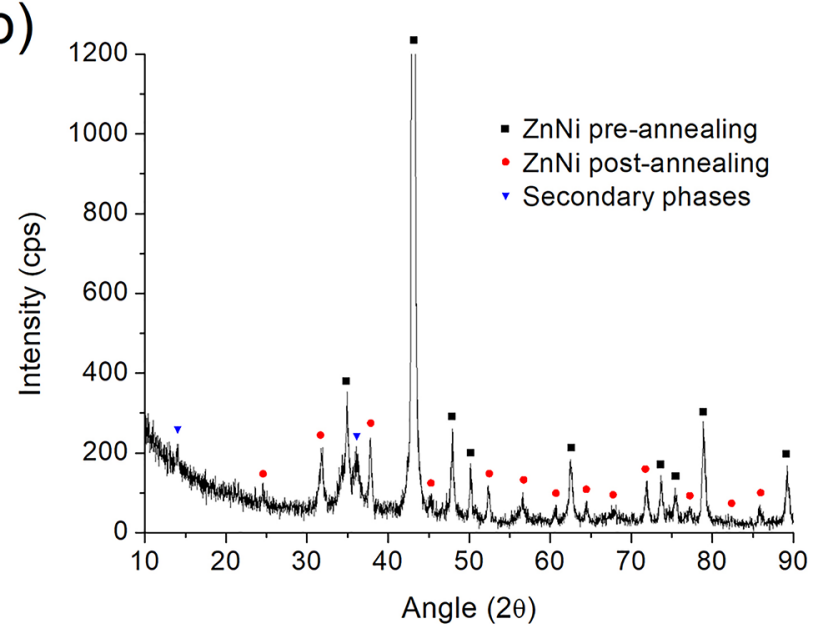

d)

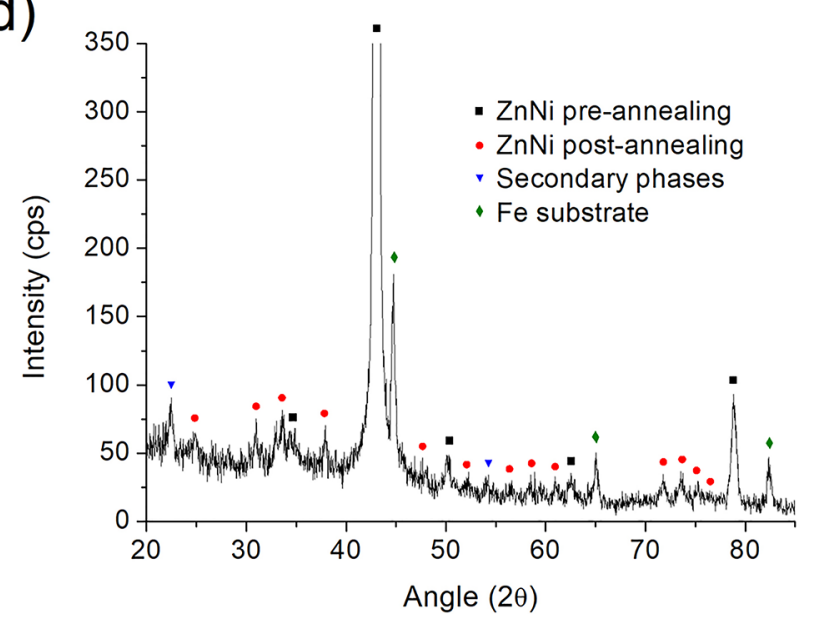

Figure 4. $\mathrm{XRD}$ graphs for as-plated $\mathrm{ZnNi}$ layers plated from $\mathrm{ChCl} / \mathrm{EG}$ (a) and from $\mathrm{EG}$ (c); $\mathrm{XRD}$ graphs for annealed $\mathrm{ZnNi}$ layers plated from $\mathrm{ChCl} / \mathrm{EG}(\mathrm{b})$ and from EG (d).

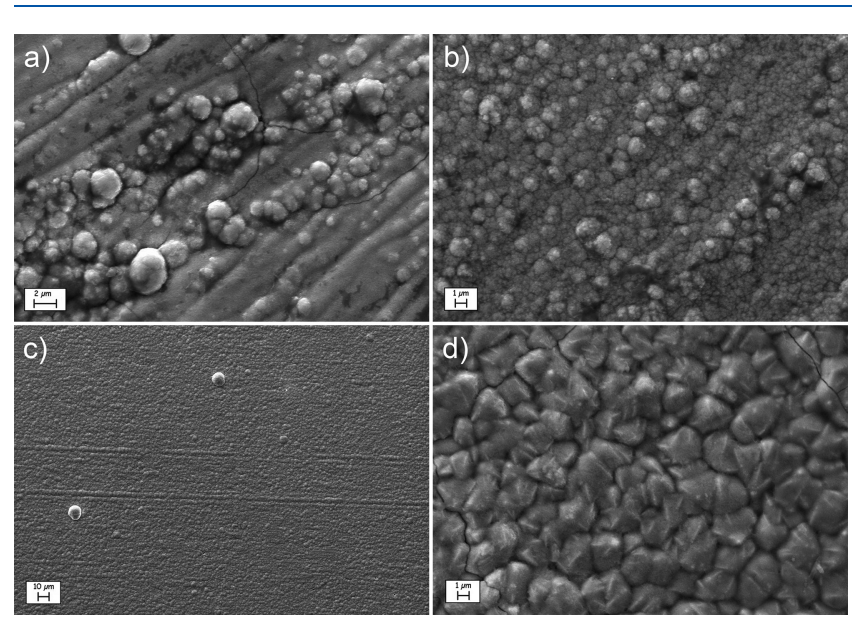

Figure 5. SEM morphology of the $\mathrm{ZnNi}$ layer electrodeposited from $\mathrm{ChCl} / \mathrm{EG}$ 1:2 (a), ChCl/EG 1:4.5 (b), and EG (c and d). Magnification values: $10,000 \times(a, b$, and d), $1000 \times(c)$.

Pure EG, contrarily to the $\mathrm{ChCl} / \mathrm{EG} \mathrm{1:2} \mathrm{mixture,} \mathrm{is} \mathrm{not} \mathrm{an}$ ionic fluid, and it presents a reduced molecular dimension with respect to choline. Consequently, its viscosity at room temperature is only 1 order of magnitude higher than water and it is roughly 4 times higher at $60{ }^{\circ} \mathrm{C}$. As a result, electrodeposition can be potentially performed also in the 40$60{ }^{\circ} \mathrm{C}$ range. The addition of metallic salts typically affects electrolyte viscosity, and for this reason, the complete $\mathrm{ZnNi}$ EG based electrolyte (containing $0.4 \mathrm{M} \mathrm{ZnCl}_{2}$ and 0.05 $\mathrm{MNiCl}_{2}$ ) was characterized and compared to pure EG. As shown in Figure 1a, the viscosity increased by $30.4 \%$ at $60{ }^{\circ} \mathrm{C}$, by $33.3 \%$ at $40{ }^{\circ} \mathrm{C}$, and by $35.7 \%$ at $25{ }^{\circ} \mathrm{C}$. All of the viscosity plots obtained follow the typical Arrhenius relationship, which exponentially correlates viscosity with temperature. ${ }^{62}$

As anticipated, another important property that both $\mathrm{ChCl} /$ EG 1:2 and EG based ZnNi electrolytes should present is a relatively high conductivity. This property is fundamental to perform efficient electrodeposition and is, for virtually all ionic liquids, linearly dependent from the reciprocal of viscosity. $\mathrm{ChCl} / \mathrm{EG} \mathrm{1:2}$ and EG are, however, radically different systems: $\mathrm{ChCl} / \mathrm{EG} 1: 2$ is an ionic fluid presenting a high intrinsic dissociation, while EG is a non-dissociated diol. Consequently, while $\mathrm{ChCl} / \mathrm{EG} \mathrm{1:2}$ is well-known for its relatively high conductivity, ${ }^{58}$ EG presents a poor conductivity (Figure 1b).

Analogously to water, however, EG readily dissolves metal salts, which can thus dissociate and provide additional conductivity. Indeed, when the $\mathrm{ZnNi} \mathrm{EG}$ based electrolyte (containing $0.4 \mathrm{M} \mathrm{ZnCl}_{2}$ and $0.05 \mathrm{M} \mathrm{NiCl}_{2}$ ) was characterized, a conductivity 2 orders of magnitude higher than pure EG was observed. This indicates a high level of dissociation for metal 
a)

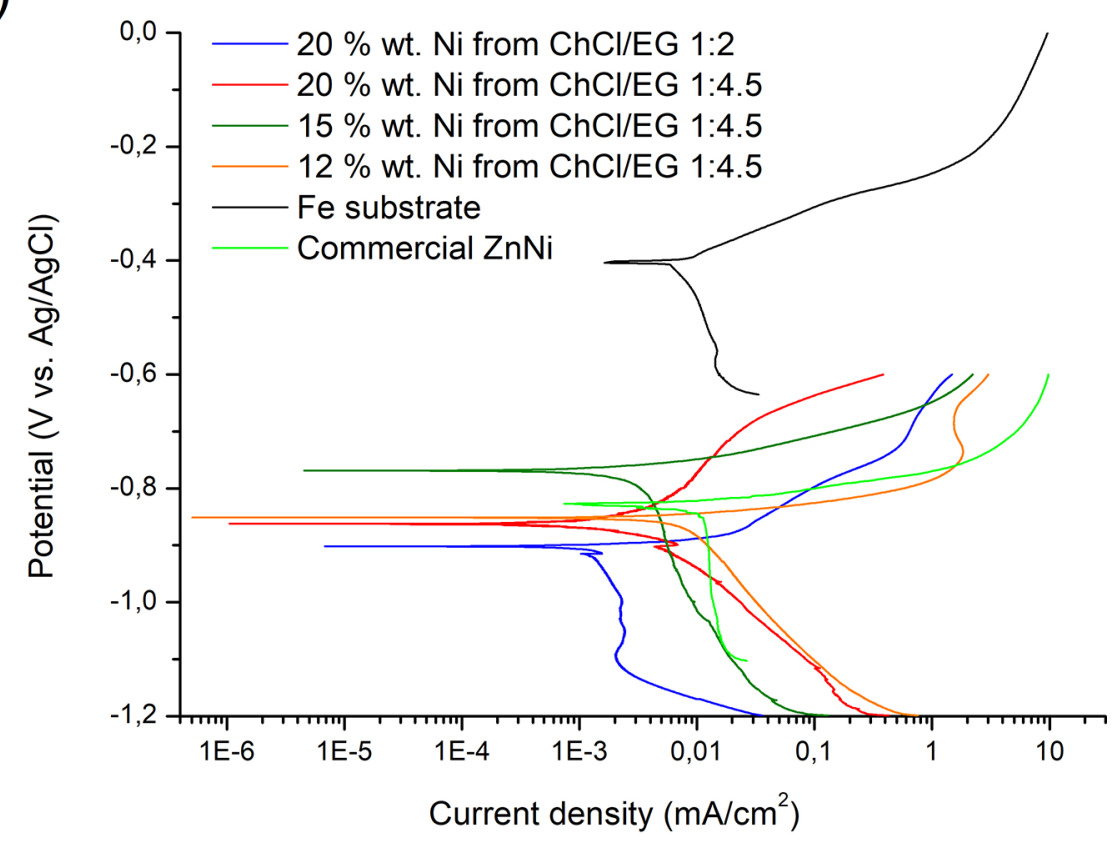

b)

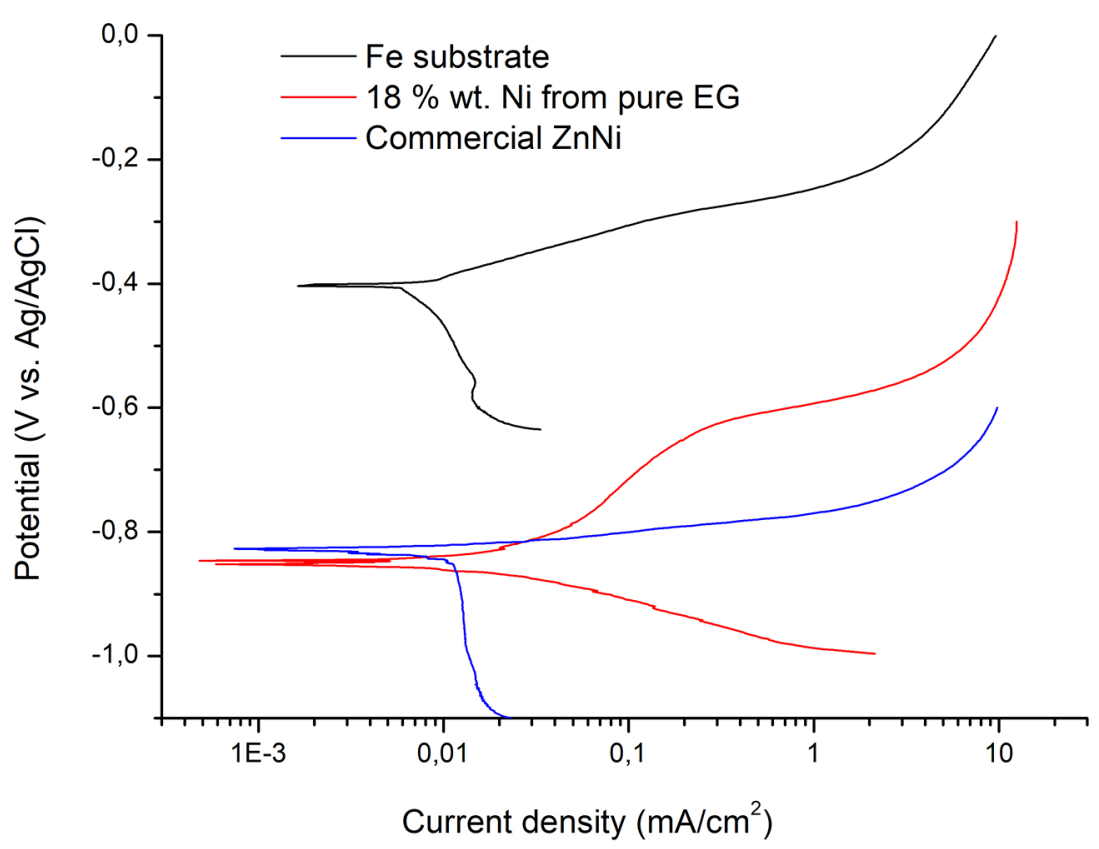

Figure 6. Potentiodynamic corrosion tests performed on $\mathrm{ZnNi}$ layers plated from $\mathrm{ChCl} / \mathrm{EG}$ (a) and from $\mathrm{EG}$ (b); the corrosion behavior of the $\mathrm{Fe}$ substrate and of a commercial $\mathrm{ZnNi}$ layer is reported for comparison.

Table 2. Corrosion Data for ZnNi Alloys and Fe Substrate

\begin{tabular}{lcc}
\multicolumn{1}{c}{ sample } & $E_{\text {corr }}(\mathrm{mV} \mathrm{vs} \mathrm{Ag} / \mathrm{AgCl})$ & $I_{\text {corr }}\left(\mu \mathrm{A} / \mathrm{cm}^{2}\right)$ \\
Fe substrate & -402 & 7.5 \\
20\% Ni wt from ChCl/EG 1:2 & -902 & 1.6 \\
20\% Ni wt from ChCl/EG 1:4.5 & -859 & 4.3 \\
15\% Ni wt from ChCl/EG 1:4.5 & -774 & 3.7 \\
12\% Ni wt from ChCl/EG 1:4.5 & -853 & 7.9 \\
18\% Ni wt from pure EG & -852 & 18.1 \\
$15 \% \mathrm{Ni}$ wt commercial ZnNi & -826 & 11.8
\end{tabular}

salts when dissolved in EG. The ZnNi EG electrolyte was characterized by a conductivity between 1.2 and $1.4 \mathrm{mS} / \mathrm{cm}$ in the $40-60{ }^{\circ} \mathrm{C}$ range, which is potentially compatible with electrodeposition.

As a result of the data obtained from the physical characterization of the different solvents, a temperature of 70 ${ }^{\circ} \mathrm{C}$ was selected for $\mathrm{ChCl} / \mathrm{EG} 1: 2$ and a temperature of $60{ }^{\circ} \mathrm{C}$ was employed for pure EG. In the case of $\mathrm{ChCl} / \mathrm{EG}$, a temperature equal to $70{ }^{\circ} \mathrm{C}$ allowed excessive energy usage to be limited. For EG, a temperature of $60{ }^{\circ} \mathrm{C}$ resulted in optimal viscosity values. 
Electrochemical Characterization. Before performing $\mathrm{ZnNi}$ electrodeposition, the electrochemical behavior of the different electrolytes was investigated. The use of $\mathrm{Pt}$ as a pseudoreference electrode was motivated by the fact that standard reference electrodes are based on aqueous solutions, which are incompatible with DESs. This, in addition to the relatively high temperatures employed, prevented the use of standard reference electrodes. Cyclic voltammetry was performed on both $\mathrm{ChCl} / \mathrm{EG} 1: 2$ and $\mathrm{EG}$ based $\mathrm{ZnNi}$ solutions. Voltammetries of $\mathrm{ChCl} / \mathrm{EG} \quad 1: 2$ and $\mathrm{EG}$ based baths containing only $\mathrm{Zn}$ or $\mathrm{Ni}$ were acquired to investigate the behavior of the single metallic species. Furthermore, a $\mathrm{ChCl}$ / EG mixture presenting an increased EG content (1:4.5 molar ratio in place of 1:2) was employed as well. In this regard, the lower concentration of $\mathrm{ChCl}$, from 33 to $15-25 \%$, would result in an increase of the ionic conductivity despite the decrease in $\mathrm{Cl}^{-}$concentration. ${ }^{59} \mathrm{Zn}, \mathrm{Ni}$, and $\mathrm{ZnNi}$ electrolytes based on this solvent were characterized because they are representative of an intermediate solution between pure EG and the stoichiometric $\mathrm{ChCl} / \mathrm{EG}$ 1:2 DES. The electrochemical behaviors of pure $\mathrm{ChCl} / \mathrm{EG}$ and $\mathrm{EG}$ have been characterized for comparison (Figure S1).

From the electrochemical point of view, the main difference between the two solvents considered, $\mathrm{ChCl} / \mathrm{EG} \mathrm{1:2}$ and $\mathrm{EG}$, is the availability of chloride ions. $\mathrm{ChCl} / \mathrm{EG} 1: 2$, due to the presence of choline chloride, contains a large amount of available $\mathrm{Cl}^{-}$, which readily forms complexes with most metal ions $\mathrm{M}^{n+}$. Coherently, chloride complexes of the kind $\mathrm{MCl}^{m-}$ have been demonstrated to be the dominant species in virtually all DESs ${ }^{15}$ where a large excess of $\mathrm{Cl}^{-}$is present. Pure EG, on the contrary, does not contain $\mathrm{Cl}^{-}$. The only chloride ions introduced in EG based baths are, eventually, the ones resulting from the metal halides added to provide reducible ions for electrodeposition. In this case, which corresponds to the situation encountered in the present work, an excess of $\mathrm{Cl}^{-}$ is not available and $\mathrm{MCl}^{m-}$ species are less prone to form. Knetsch et al. demonstrated, however, that ethylene glycol forms mixed complexes of the kind $\mathrm{M}_{n}(\mathrm{EG})_{m} \mathrm{Cl}_{p}$ with metal halides. ${ }^{63}$ Such mixed complexes are characterized by high stability, and they can be easily isolated. Ruttink et al. and Maltanava et al. described the formation of $\mathrm{M}_{n}(\mathrm{EG})_{m} \mathrm{Cl}_{p}$ complexes as well. ${ }^{50,64} \mathrm{~A}$ similar situation may occur also in pure EG based electrolytes, whose environment presents a favorable stoichiometry.

Parts a and $\mathrm{b}$ of Figure 2 depict the electrochemical behavior of $\mathrm{Zn}(\mathrm{II})$ in $\mathrm{ChCl} / \mathrm{EG}$ and $\mathrm{EG}$, respectively. The three

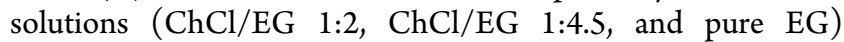
contained the same amount of zinc salt: $0.2 \mathrm{M} \mathrm{ZnCl}_{2}$. Proper practice imposes, where possible, to evaluate the potential of the redox peaks $\left(E_{\text {peak }}\right)$ for each electrochemical reaction taking place in an electrolyte. In some cases, however, no clear redox peaks are visible. This is the case of many voltammograms reported in the present work, and for this reason, the reaction onset potential $\left(E_{\text {on }}\right)$ was evaluated to allow full data comparison. In $\mathrm{ChCl} / \mathrm{EG}$ 1:2 (Figure 2a), the $\mathrm{Zn}^{2+} \rightarrow \mathrm{Zn}^{0}$ reduction $\left(\mathrm{Zn}_{\text {red }}\right.$ in the graph $)$ starts around $-1.01 \mathrm{~V}$ vs $\mathrm{Pt}$ and presents a peak around $-1.2 \mathrm{~V}$ vs Pt. The situation is similar when the $\mathrm{ChCl} / \mathrm{EG}$ ratio is reduced to $1: 4.5$ (Figure 2a), with $E_{\text {on }}$ for $\mathrm{Zn}_{\text {red }}$ at $-1.02 \mathrm{~V}$ vs Pt and $E_{\text {peak }}$ around $-1.2 \mathrm{~V}$ vs Pt. The behavior observed in the case of $\mathrm{ChCl} / \mathrm{EG} \mathrm{1:2}$ and 1:4.5 presents important analogies with other existing studies on $\mathrm{Zn}$ deposition from DESs. ${ }^{65,66}$ Conversely, in EG (Figure 2b), the $\mathrm{Zn}_{\text {red }}$ reaction starts at $-1.11 \mathrm{~V}$ vs $\mathrm{Pt}$ and does not present a defined peak. This value is slightly lower than the one that was observed in the case of $\mathrm{Zn}^{2+}$ reduction in an EG based electrolyte containing zinc acetate. ${ }^{47}$ The reason may reside in the different complexation: an acetate containing EG electrolyte does not present chloride moieties, and $\mathrm{Zn}$ is consequently forced to form different complexes. ${ }^{47}$ In both cases, finally, a broad anodic stripping peak $\left(\mathrm{Zn}_{\mathrm{ox}}\right)$ can be observed.

A similar approach was followed to investigate the behavior of $\mathrm{Ni}(\mathrm{II})$ in $\mathrm{ChCl} / \mathrm{EG}$ and $\mathrm{EG}$ (Figure $2 \mathrm{c}$ and $\mathrm{d}$ ). The three

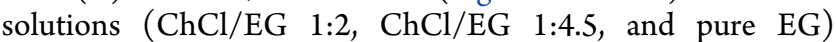
contained the same amount of nickel salt: $0.2 \mathrm{M} \mathrm{NiCl}_{2}$. In the case of $\mathrm{Ni}$ electroreduction, which is identified by $\mathrm{Ni}_{\text {red }}$ in the graphs and takes place as $\mathrm{Ni}^{2+} \rightarrow \mathrm{Ni}^{0}$, the situation presents important differences between the $\mathrm{ChCl} / \mathrm{EG}$ and the $\mathrm{EG}$ based electrolytes. In $\mathrm{ChCl} / \mathrm{EG} \mathrm{1:2} \mathrm{(Figure} \mathrm{2c),} \mathrm{reduction} \mathrm{starts}$ $\left(E_{\text {on }}\right)$ around $-0.52 \mathrm{~V}$ vs $\mathrm{Pt}$, which is a value slightly higher than the one $(-0.62 \mathrm{~V}$ vs $\mathrm{Pt})$ observed in $\mathrm{ChCl} / \mathrm{EG} 1: 4.5$

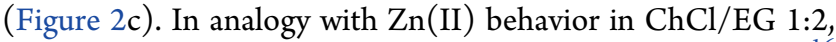
also $\mathrm{Ni}(\mathrm{II})$ presents similarities with the existing literature. ${ }^{16}$ The pure EG based electrolyte presents a value of $E_{\text {on }}$ for $\mathrm{Ni}_{\text {red }}$ equal to $-0.67 \mathrm{~V}$ vs Pt. The observed variation of $E_{\text {on }}$ with respect to the ratio between $\mathrm{ChCl}$ and $\mathrm{EG}$ is indicative of an increasing complexation level when more EG is present in the electrolyte. A reduction peak is visible in the case of $\mathrm{ChCl} / \mathrm{EG}$ $1: 2$ around $-0.8 \mathrm{~V}$ vs $\mathrm{Pt}$, whereas the curve obtained in EG presents a plateau after $-0.65 \mathrm{~V}$ vs Pt. The presence of such a plateau is indicative of a diffusion-limited reaction. A major difference between the two electrolytes resides in the anodic branch of the voltammetries. For $\mathrm{ChCl} / \mathrm{EG}$ based electrolytes, an anodic peak $\left(\mathrm{Ni}_{\text {ox }}\right)$ presenting a reduced intensity is visible around $0.2 \mathrm{~V}$ vs Pt. Conversely, in the case of EG, a broad anodic stripping peak can be seen, which is indicative of a more favorable anodic reaction kinetic.

Voltammetries were then performed on the complete $\mathrm{ZnNi}$ solutions, with either $\mathrm{ChCl} / \mathrm{EG}$ or EG as solvents (Figure 2e and $\mathrm{f}$ ). The $\mathrm{ChCl} / \mathrm{EG}$ based bath contained $0.2 \mathrm{M} \mathrm{Zn(II)} \mathrm{and}$ $0.13 \mathrm{M} \mathrm{Ni}(\mathrm{II})$, while the EG based bath contained $0.2 \mathrm{M}$ $\mathrm{Zn}$ (II) and $0.15 \mathrm{M} \mathrm{Ni}$ (II). In all of the cases, a neat separation between the two reduction peaks was observed. In $\mathrm{ChCl} / \mathrm{EG}$ $1: 2$, Ni reduction $\left(\mathrm{Ni}_{\text {red }}\right)$ started around $-0.5 \mathrm{~V}$ vs $\mathrm{Pt}$ and peaked around $-0.8 \mathrm{~V}$ vs $\mathrm{Pt}$, while $\mathrm{Zn}_{\text {red }}$ started at $-1.17 \mathrm{~V}$ vs Pt. In $\mathrm{ChCl} / \mathrm{EG} 1: 4.5, \mathrm{Ni}$ reduction $\left(\mathrm{Ni}_{\text {red }}\right)$ started around $-0.55 \mathrm{~V}$ vs $\mathrm{Pt}$ and peaked around $-0.8 \mathrm{~V}$ vs $\mathrm{Pt}$, while $\mathrm{Zn}_{\text {red }}$ started at $-1.07 \mathrm{~V}$ vs $\mathrm{Pt}$. In pure EG, finally, Ni reduction $\left(\mathrm{Ni}_{\text {red }}\right)$ started around $-0.68 \mathrm{~V}$ vs $\mathrm{Pt}$, while $\mathrm{Zn}_{\text {red }}$ started at -1.17 V vs Pt. Different anodic peaks can be observed in the anodic branch of the $\mathrm{ZnNi}$ voltammograms. These results from the progressive stripping of $\mathrm{Zn}$ and $\mathrm{Ni}$ are generically identified as $\left(\mathrm{Zn}_{\mathrm{ox}} / \mathrm{Ni}_{\mathrm{ox}}\right)$.

Table 1 summarizes all of the data obtained and allows a direct comparison between $\mathrm{Zn}, \mathrm{Ni}$, and $\mathrm{ZnNi}$ containing electrolytes.

A first important consideration comes from the comparison between $E_{\text {on }}$ values in different solvents. $E_{\text {on }}$ values present the tendency to increase when the relative concentration of EG in the electrolyte increases. This is probably indicative of a higher level of complexation. When comparing $\mathrm{ZnNi}$ electrolytes with the pure metal solutions, it can be observed that $\mathrm{Zn}$ and $\mathrm{Ni} E_{\text {on }}$ values shift. The $\mathrm{Ni}$ reduction onset tendentially occurs at more positive potentials, while $\mathrm{Zn} E_{\text {on }}$ shifts toward more negative values.

Figure S2 describes the effect of varying $\mathrm{Zn}(\mathrm{II}) / \mathrm{Ni}(\mathrm{II})$ relative ratios on the voltammograms. As expectable, curves 
obtained in $\mathrm{ChCl} / \mathrm{EG}$ progressively change in intensity when the $\mathrm{Zn}(\mathrm{II}) / \mathrm{Ni}(\mathrm{II})$ ratio varies. This tendency, which is correlated to the variation of the overall quantity of metal salts present in the solution, is evident also in the case of EG based electrolytes.

Potentiostatic ZnNi Electrodeposition. Potentiostatic $\mathrm{ZnNi}$ depositions were performed on steel from both $\mathrm{ChCl} /$ EG 1:2 and EG based electrolytes. Also, in this case, a $\mathrm{ChCl} /$ EG 1:4.5 electrolyte was used together with $\mathrm{ChCl} / \mathrm{EG} 1: 2$ and EG to investigate an intermediate anions complexation condition. Figure 3 represents the results obtained in terms of composition, determined via X-ray fluorescence spectroscopy (XRF).

For $\mathrm{ChCl} / \mathrm{EG}$, the potential was scanned between $-0.8 \mathrm{~V}$ vs $\mathrm{Pt}$ and $-1.6 \mathrm{~V}$ vs $\mathrm{Pt}$, mapping thus the resulting $\mathrm{ZnNi}$ layer composition. It is interesting to notice that, at higher EG

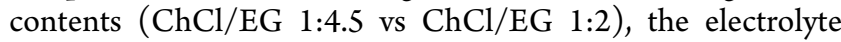
tends to yield higher $\mathrm{Ni}$ concentrations (Figure 3a). This appears counterintuitive, since higher EG concentrations decrease $E_{\text {on }}$ for $\mathrm{Ni}_{\text {red }}$ (decreasing thus the $\Delta E_{\text {on }}$ between $\mathrm{Zn}_{\text {red }}$ and $\left.\mathrm{Ni}_{\text {red }}\right)$. This effect, visible in Table 1 , should lead to a decrease in the concentration of the more noble metal, i.e., $\mathrm{Ni}$. It cannot be ignored, however, the fact that $\mathrm{ZnNi}$ deposits following an anomalous co-deposition mechanism. ${ }^{4}$ Consequently, the effect of complexation can be different with respect to the normal co-deposition mechanism and can affect, besides deposition potentials, also the surface reactions at the base of anomalous co-deposition. Some literature studies ${ }^{67,68}$ suggest that, in the case of $\mathrm{ZnNi}$ co-deposition in aqueous solutions, a higher complexation level increases $\mathrm{Ni}$ content. The trend is further confirmed by looking at Figure 3b, where compositional data obtained from the pure EG $\mathrm{ZnNi}$ electrolyte are plotted together with the data from $\mathrm{ChCl} / \mathrm{EG}$ $1: 4.5$ and $\mathrm{ChCl} / \mathrm{EG} 1: 2$. In this case, the potential ranged between -1.2 and $-2 \mathrm{~V}$ vs Pt. Once again, a significant increase in $\mathrm{Ni}$ content was observed moving from $\mathrm{ChCl} / \mathrm{EG}$ to pure EG (thus increasing the EG content).

Figure $3 c$ depicts the effect of the $\mathrm{Zn}$ (II)/Ni(II) ratio on the final layer composition in a $\mathrm{ChCl} / \mathrm{EG} \mathrm{1:4.5} \mathrm{electrolyte.} \mathrm{It} \mathrm{is} \mathrm{not}$ surprising that, by decreasing the amount of $\mathrm{Ni}^{2+}$ in the bath, i.e., increasing the $\mathrm{Zn}(\mathrm{II}) / \mathrm{Ni}$ (II) ratio, the final $\mathrm{Ni}$ amount in the layer decreases. The same effect was observed in the case of the EG based electrolyte (Figure 3d).

Anomalous co-deposition is defined as follows: the percentage of the more noble metal in the deposit is lower than the percentage of the same in the electrolyte. This condition can be conveniently represented, in the case of $\mathrm{ZnNi}$ co-deposition, in a diagram of the kind \% mol. $\mathrm{Ni}$ in the electrolyte vs \% mol. $\mathrm{Ni}$ in the deposit (Figure $3 \mathrm{e}$ and $\mathrm{f}$ ). The black line represents the condition in which the Ni percentage in the bath equals the $\mathrm{Ni}$ concentration in the deposited layer. Thus, $\mathrm{ZnNi}$ co-deposition can be defined as anomalous when the resulting layer presents a composition that lies below the line. If data reported in Figure $3 \mathrm{c}$ and $\mathrm{d}$ are plotted as atomic percentages, the result visible in Figure $3 \mathrm{e}$ and $\mathrm{f}$ is obtained. It appears that $\mathrm{ZnNi}$ co-deposition from $\mathrm{ChCl} / \mathrm{EG} 1: 4.5$ and $\mathrm{EG}$ presents an anomalous character, especially at lower deposition potentials. This effect is related to the anomalous codeposition mechanism: since $\mathrm{Ni}$ deposition is partially inhibited by the $\mathrm{Zn}$ deposition reaction, the effect is more evident when the percentage of $\mathrm{Zn}$ is higher (at low deposition potentials). Both electrolytes start to show anomalous codeposition at potentials lower than $-1.2 \mathrm{~V}$ vs Pt.
Electrodeposited ZnNi Phase Composition. From the phase composition point of view, $\mathrm{ZnNi}$ alloys in the 15-26\% at. Ni should be totally composed of a cubic $\gamma \mathrm{ZnNi}$ phase. ${ }^{69}$ This is only partially true for electrodeposited $\mathrm{ZnNi}$, as already demonstrated in the literature. ${ }^{70,71}$ In particular, plated $\mathrm{ZnNi}$ typically forms a metastable $\gamma$ phase, which is characterized by a lower degree of ordering with respect to the equilibrium cubic $\gamma$ phase. This behavior is a direct consequence of the technique employed to obtain the layer. Electrodeposition, as a matter of fact, is a deposition methodology that often works under nonequilibrium conditions and forms metastable structures $^{72}$ characterized by an enthalpy higher than their equilibrium counterparts. In electroplated $\mathrm{ZnNi}$, in particular, such an increased level of enthalpy can be associated with $\mathrm{Ni}$ atoms that are randomly distributed in the lattice positions instead of being located in preferential sublattice sites.

Formation of a metastable $\gamma \mathrm{ZnNi}$ phase, originally observed by performing XRD on layers obtained from aqueous solutions, ${ }^{70,71}$ is confirmed also in the case of layers plated from nonaqueous electrolytes like $\mathrm{ChCl} / \mathrm{EG}$ and $\mathrm{EG}$ (Figure 4). In particular, parts $a$ and $b$ of Figure 4 report the XRD spectra obtained from a $\mathrm{ZnNi}$ layer $(20 \%$ wt $\mathrm{Ni}$ ) plated from $\mathrm{ChCl} / \mathrm{EG} \mathrm{1:2}$ before and after annealing, respectively. Parts c and $\mathrm{d}$ of Figure 4 report the XRD spectra obtained from a $\mathrm{ZnNi}$ layer (18\% wt $\mathrm{Ni}$ ) plated from EG before and after annealing, respectively. As-plated $\mathrm{ZnNi}$ layers present a characteristic XRD pattern, which does not fully correspond to any equilibrium $\mathrm{ZnNi}$ intermetallic. Experimental features match the positions of calculated XRD peaks for a $\gamma$ structure with $\mathrm{Ni}$ atoms randomly distributed over all atomic sites (Table S1), demonstrating thus the presence of a metastable phase also in the case of $\mathrm{ZnNi}$ plated from $\mathrm{ChCl} / \mathrm{EG}$ and $\mathrm{EG}$.

After annealing, layers from both $\mathrm{ChCl} / \mathrm{EG}$ and $\mathrm{EG}$ developed the complete set of $\gamma$ phase peaks. The new peaks that appeared as a consequence of annealing are evident by comparing Figure $4 \mathrm{a}$ and $\mathrm{c}$ (before annealing) with Figure $4 \mathrm{~b}$ and $d$ (after annealing). Such new features, once again, find exact correspondence in the calculated peaks (Table S1). The annealing treatment may promote atomic rearrangement, leading to a more stable structure where $\mathrm{Ni}$ atoms occupy the outer tetrahedral sites in the cubic cell. Nevertheless, atomic rearrangement might be incomplete after the annealing run and a fraction of $\mathrm{Ni}$ atoms must occupy sublattice sites other than the outer tetrahedral ones. Actually, these sites are fully occupied with a $\mathrm{Ni}$ percentage of $14 \mathrm{wt} \%$ and the composition of the examined layers is beyond this limit. Therefore, it is not surprising that the diffraction spectrum of the annealed layers is still consistent with the calculated XRD pattern of the random solid solution.

Crystallite size was evaluated for layers obtained from both $\mathrm{ChCl} / \mathrm{EG}$ and EG employing the well-known Scherrer equation. Two intense peaks (330/411 and 552/633) were employed, and their full width at half-maximum (fwhm) was evaluated. The mean crystallite size for $\mathrm{ZnNi}$ from $\mathrm{ChCl} / \mathrm{EG}$ was found to be $17.4 \pm 0.52 \mathrm{~nm}$, while the mean crystallite size for $\mathrm{ZnNi}$ from $\mathrm{EG}$ was found to be equal to $11.06 \pm 1.84 \mathrm{~nm}$. As expected, the crystallite size increased as a consequence of annealing. In particular, it was found to be equal to $37.61 \pm$ $0.16 \mathrm{~nm}$ in the case of $\mathrm{ChCl} / \mathrm{EG}$ and $27.44 \pm 3.71 \mathrm{~nm}$ in the case of EG.

Some unidentified small peaks are present in Figure 4. Such features, however, are all located at low angles, suggesting the presence of minor quantities of oxides or hydroxides on the 
surface. No difference in the phase composition was observed between the $\mathrm{ZnNi}$ layers deposited from $\mathrm{ChCl} / \mathrm{EG} \mathrm{1:2,} \mathrm{ChCl}$ / EG $1: 4.5$, or pure EG.

ZnNi Surface Morphology. SEM was employed to morphologically characterize the surface of $\mathrm{ZnNi}$ layers deposited from $\mathrm{ChCl} / \mathrm{EG} \mathrm{1:2,} \mathrm{ChCl} / \mathrm{EG} \mathrm{1:4.5}$, and pure EG. Figure 5 depicts the result obtained.

The layer obtained from $\mathrm{ChCl} / \mathrm{EG} \mathrm{1:2} \mathrm{(Figures} \mathrm{5a} \mathrm{and} \mathrm{S3;}$ $\left.-1.2 \mathrm{~V}, 0.2 \mathrm{M} \mathrm{ZnCl}_{2}+0.13 \mathrm{M} \mathrm{NiCl}_{2} \cdot 6 \mathrm{H}_{2} \mathrm{O}\right)$ showed a relatively coarse morphology (Figure $\mathrm{S} 3$ ), characterized by the presence of irregular nodular structures on the surface (Figure $5 \mathrm{a}$ ). In the case of $\mathrm{ChCl} / \mathrm{EG} \mathrm{1:4.5} \mathrm{(Figure} 5 \mathrm{~b} ;-1.3 \mathrm{~V}, 0.2 \mathrm{M}$ $\mathrm{ZnCl}_{2}+0.13 \mathrm{M} \mathrm{NiCl}_{2} \cdot 6 \mathrm{H}_{2} \mathrm{O}$ ) and pure EG (Figure $5 \mathrm{c}$ and $\mathrm{d}$; $-1.8 \mathrm{~V}, 0.4 \mathrm{M} \mathrm{ZnCl}_{2}+0.05 \mathrm{M} \mathrm{NiCl}_{2} \cdot 6 \mathrm{H}_{2} \mathrm{O}$ ), conversely, the morphology became more fine-grained and uniform. At higher magnification (Figure 5d), the surface of the layer obtained from EG evidenced a uniform distribution of micrometric semiprismatic nodules on the surface. The mean thickness of the samples depicted in figure was between 3 and $4 \mu \mathrm{m}$. Some minor cracks are evident in Figure 5a and d, probably as a result of internal stress accumulation in the layer. Such cracks became more evident at increasing layer thickness, as visible in Figure S4 (layer thickness $13 \mu \mathrm{m}$ ).

EDS graphs (Figures S5, S6, and S7) evidenced a negligible chlorine contamination of the layer. This demonstrates that $\mathrm{Cl}^{-}$ions present in the electrolytes are not actively incorporated in the final coatings. Limited oxygen and carbon contamination was detected. In general, layers obtained from both $\mathrm{ChCl} / \mathrm{EG}$ and pure EG are characterized by high purity.

ZnNi Corrosion Behavior. The corrosion behavior of the electrodeposited $\mathrm{ZnNi}$ coatings was investigated performing linear scan potentiometry tests (Figure 6). Corrosion potentials and currents of $\mathrm{ZnNi}$ alloys plated from $\mathrm{ChCl} / \mathrm{EG}$ $1: 2, \mathrm{ChCl} / \mathrm{EG} \mathrm{1:4.5}$, and pure EG were compared with the corrosion properties of uncoated steel in order to estimate their corrosion protection. Moreover, the behavior of a $\mathrm{ZnNi}$ layer (14\% wt $\mathrm{Ni}$ ) plated from a commercial aqueous alkaline $\mathrm{ZnNi}$ electrolyte (Glovel 800 by GLOMAX) was acquired and used for comparison. Optimal conditions provided by the manufacturer were employed for the deposition of the commercial $\mathrm{ZnNi}$ sample.

Tafel extrapolation was used to calculate the corrosion potentials $\left(E_{\text {corr }}\right)$ and the corrosion current densities $\left(I_{\text {corr }}\right)$ of $\mathrm{ZnNi}$ alloys in $3.5 \% \mathrm{NaCl}$. The result obtained is shown visually in Figure 6 and numerically in Table 2.

As expected, the corrosion potential of all $\mathrm{ZnNi}$ alloys was more negative if compared to steel $(-440 \mathrm{mV}$ vs $\mathrm{Ag} / \mathrm{AgCl})$ and slightly higher than zinc (which has corrosion potentials not higher than $-1000 \mathrm{mV}$ vs $\mathrm{Ag} / \mathrm{AgCl}$ in $3.65 \%$ wt $\mathrm{NaCl}$ solutions ${ }^{73}$ ) as a consequence of their nickel content. In $\mathrm{ZnNi}$, during corrosion, $\mathrm{Zn}$ dissolves preferentially and leaves a layer enriched with Ni. This layer can act as a physical barrier to slow down further corrosion. ${ }^{74}$ Despite the formation of this protective layer, the samples did not show evident signs of passivity. This behavior is in accordance with the literature, where $\mathrm{ZnNi}$ layers tested in $\mathrm{NaCl}$ solution behaved in an analogous way. ${ }^{75-78}$

In general, all of the alloys obtained presented corrosion potentials similar to the commercial $\mathrm{ZnNi}$ sample. The maximum $E_{\text {corr }}$ difference with respect to the Glovel plated $\mathrm{ZnNi}$ layer $E_{\text {corr }}$ was $76 \mathrm{mV}$ vs $\mathrm{Ag} / \mathrm{AgCl}$ toward more negative potentials (obtained from the $20 \% \mathrm{Ni}$ wt from the $\mathrm{ChCl} / \mathrm{EG}$ 1:2 sample) and $52 \mathrm{mV}$ vs $\mathrm{Ag} / \mathrm{AgCl}$ toward more positive potentials (obtained from the $15 \% \mathrm{Ni}$ wt from the $\mathrm{ChCl} / \mathrm{EG}$ $1: 4.5$ sample). By considering the data obtained, it appears that $\mathrm{ZnNi}$ alloys deposited from $\mathrm{ChCl} / \mathrm{EG}$ (both $1: 2$ and 1:4.5) present corrosion currents lower than commercial $\mathrm{ZnNi}$, which slightly depend on $\mathrm{Ni}$ content. $\mathrm{ZnNi}$ plated from $\mathrm{EG}$, conversely, showed corrosion currents comparable to commercial Glovel $\mathrm{ZnNi}$.

\section{CONCLUSIONS}

Choline chloride/ethylene glycol and pure ethylene glycol were successfully employed as non-aqueous solvents for $\mathrm{ZnNi}$ deposition. From the electrochemical point of view, both $\mathrm{Zn}$ (II) and $\mathrm{Ni}$ (II) showed a complexation level dependent on the relative ratio between $\mathrm{ChCl}$ and $\mathrm{EG}$. In particular, the separation between reduction onset potentials decreased by increasing EG concentration. This is indicative of a stronger complexation, which can be explained with the possible disappearance of $\mathrm{MCl}^{m-}$ complexes in favor of $\mathrm{M}_{n}(\mathrm{EG})_{m} \mathrm{Cl}_{p}$ mixed EG-chloride moieties. $\mathrm{ZnNi}$ electrodeposition was demonstrated to follow, analogously to aqueous solutions, an anomalous co-deposition mechanism. Potentiostatic deposition tests evidenced an anomalous behavior especially at potentials lower than $-1.2 \mathrm{~V}$ vs $\mathrm{Pt}$, where $\mathrm{Zn}$ co-deposited preferentially. For all of the electrolytes studied, it was possible to obtain a composition range between 10 and $20 \%$ wt, which is the most interesting for corrosion protection applications. $\mathrm{ZnNi}$ layers were found to be free from substantial contamination. The phase composition of $\mathrm{ZnNi}$ coatings plated from both $\mathrm{ChCl} / \mathrm{EG}$ and EG was studied via XRD. Asplated layers were all characterized by the presence of a metastable $\mathrm{ZnNi} \gamma$ phase, similarly to layers obtained from aqueous solutions. A good corrosion resistance, equivalent or better with respect to the commercial $\mathrm{ZnNi}$ layer, was observed during potentiodynamic polarization tests. Corrosion currents ranged between 1.6 and $18.1 \mu \mathrm{A} / \mathrm{cm}^{2}$, with a value of $11.8 \mu \mathrm{A} / \mathrm{cm}^{2}$ for commercial $\mathrm{ZnNi}$. Corrosion potentials were found to vary between -902 and $-774 \mathrm{mV}$ vs $\mathrm{Ag} / \mathrm{AgCl}$, with a value of $-826 \mathrm{mV}$ vs $\mathrm{Ag} / \mathrm{AgCl}$ for commercial $\mathrm{ZnNi}$. Corrosion properties were found to vary, as expected, as a result of the solution employed to deposit the layer. In conclusion, the results obtained justify the interest in nonaqueous electrolytes for $\mathrm{ZnNi}$ deposition.

\section{ASSOCIATED CONTENT}

\section{Supporting Information}

The Supporting Information is available free of charge at https://pubs.acs.org/doi/10.1021/acs.jpcb.0c04784.

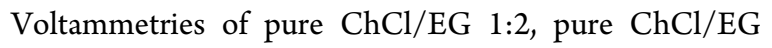
1:4.5, and pure EG; voltammetries of $\mathrm{ZnNi}$ electrolytes with different $\mathrm{Zn}(\mathrm{II}) / \mathrm{Ni}$ (II) ratios; calculated XRD peaks for a $\mathrm{ZnNi} \gamma$ phase containing randomly placed $\mathrm{Ni}$ atoms; SEM images of $\mathrm{ZnNi}$ layers plated from $\mathrm{ChCl}$ / EG 1:2, $\mathrm{ChCl} / \mathrm{EG} \mathrm{1:4.5,} \mathrm{and} \mathrm{EG;} \mathrm{and} \mathrm{EDS} \mathrm{analysis} \mathrm{of}$ $\mathrm{ZnNi}$ layers plated from $\mathrm{ChCl} / \mathrm{EG} \mathrm{1:2,} \mathrm{ChCl} / \mathrm{EG} \mathrm{1:4.5}$, and EG (PDF)

\section{AUTHOR INFORMATION}

\section{Corresponding Author}

L. Magagnin - Dipartimento di Chimica, Materiali e Ingegneria Chimica Giulio Natta, 20131 Milano, Italy; (1) orcid.org/0000-0001-5553-6441;

Email: luca.magagnin@polimi.it 


\section{Authors}

R. Bernasconi - Dipartimento di Chimica, Materiali e Ingegneria Chimica Giulio Natta, 20131 Milano, Italy; (1) orcid.org/0000-0003-2193-8017

G. Panzeri - Dipartimento di Chimica, Materiali e Ingegneria Chimica Giulio Natta, 20131 Milano, Italy

G. Firtin - Dipartimento di Chimica, Materiali e Ingegneria Chimica Giulio Natta, 20131 Milano, Italy

B. Kahyaoglu - Dipartimento di Chimica, Materiali e Ingegneria Chimica Giulio Natta, 20131 Milano, Italy

L. Nobili - Dipartimento di Chimica, Materiali e Ingegneria Chimica Giulio Natta, 20131 Milano, Italy

Complete contact information is available at:

https://pubs.acs.org/10.1021/acs.jpcb.0c04784

\section{Notes}

The authors declare no competing financial interest.

\section{ACKNOWLEDGMENTS}

The authors received no financial support for the research, authorship, or publication of the present work.

\section{REFERENCES}

(1) Fratesi, R.; Roventi, G. Corrosion Resistance of Zn-Ni Alloy Coatings in Industrial Production. Surf. Coat. Technol. 1996, 82 (12), $158-164$.

(2) Fashu, S.; Khan, R. Recent Work on Electrochemical Deposition of $\mathrm{Zn}-\mathrm{Ni}$ (-X) Alloys for Corrosion Protection of Steel. Anti-Corros. Methods Mater. 2019, 66 (1), 45-60.

(3) Roventi, G.; Fratesi, R.; Della Guardia, R. A.; Barucca, G. Normal and Anomalous codeposition of $\mathrm{Zn}-\mathrm{Ni}$ Alloys from Chloride Bath. J. Appl. Electrochem. 2000, 30 (2), 173-179.

(4) Brenner, A. Electrodeposition of Alloys: PRINCIPLES and PRACTICE. Electrodepos. Alloy. 1963, No. ii.

(5) Zech, N. Anomalous Codeposition of Iron Group Metals: II. Mathematical Model 1999, 146, 2892.

(6) Kwon, M.; Jo, D.-h.; Cho, S. H.; Kim, H. T.; Park, J.-T.; Park, J. M. Characterization of the Influence of Ni Content on the Corrosion Resistance of Electrodeposited Zn-Ni Alloy Coatings. Surf. Coat. Technol. 2016, 288, 163-170.

(7) Yang, H. Y.; Guo, X. W.; Chen, X. B.; Wang, S. H.; Wu, G. H.; Ding, W. J.; Birbilis, N. On the Electrodeposition of Nickel-Zinc Alloys from a Eutectic-Based Ionic Liquid. Electrochim. Acta 2012, 63, 131-138.

(8) Pereira, N. M.; Pereira, C. M.; Araújo, J. P.; Silva, A. F. Influence of Amines on the Electrodeposition of Zn-Ni Alloy from a EutecticType Ionic Liquid. J. Electrochem. Soc. 2015, 162 (8), D325-D330.

(9) Fashu, S.; Gu, C. D.; Wang, X. L.; Tu, J. P. Influence of Electrodeposition Conditions on the Microstructure and Corrosion Resistance of Zn-Ni Alloy Coatings from a Deep Eutectic Solvent. Surf. Coat. Technol. 2014, 242, 34-41.

(10) Fashu, S.; Gu, C. D.; Zhang, J. L.; Huang, M. L.; Wang, X. L.; Tu, J. P. Effect of EDTA and NH4Cl Additives on Electrodeposition of $\mathrm{Zn}-\mathrm{Ni}$ Films from Choline Chloride-Based Ionic Liquid. Trans. Nonferrous Met. Soc. China 2015, 25 (6), 2054-2064.

(11) Li, R.; Dong, Q.; Xia, J.; Luo, C.; Sheng, L.; Cheng, F.; Liang, J. Electrodeposition of Composition Controllable $\mathrm{Zn}-\mathrm{Ni}$ Coating from Water Modified Deep Eutectic Solvent. Surf. Coat. Technol. 2019, 366, $138-145$.

(12) Abbott, A. P.; Boothby, D.; Capper, G.; Davies, D. L.; Rasheed, R. K. Deep Eutectic Solvents Formed between Choline Chloride and Carboxylic Acids: Versatile Alternatives to Ionic Liquids. J. Am. Chem. Soc. 2004, 126 (29), 9142-9147.

(13) Abbott, A. P.; McKenzie, K. J. Application of Ionic Liquids to the Electrodeposition of Metals. Phys. Chem. Chem. Phys. 2006, 8, $4265-4279$.
(14) Bernasconi, R.; Panzeri, G.; Accogli, A.; Liberale, F.; Nobili, L.; Magagnin, L. Electrodeposition from Deep Eutectic Solvents. In Progress and Developments in Ionic Liquids; InTech, 2017.

(15) Smith, E. L.; Abbott, A. P.; Ryder, K. S. Deep Eutectic Solvents (DESs) and Their Applications. Chem. Rev. 2014, 114 (21), 1106011082.

(16) Abbott, A. P.; Ballantyne, A.; Harris, R. C.; Juma, J. A.; Ryder, K. S. A Comparative Study of Nickel Electrodeposition Using Deep Eutectic Solvents and Aqueous Solutions. Electrochim. Acta 2015, 176, $718-726$

(17) Smith, E. L. Deep Eutectic Solvents (DESs) and the Metal Finishing Industry: Where Are They Now? Trans. Inst. Met. Finish. 2013, 91 (5), 241-248.

(18) Huynh, T. C.; Dao, Q. P. D.; Truong, T.-N.; Doan, N.-G.; Ho, S.-L. Electrodeposition of Aluminum on Cathodes in Ionic Liquid Based Choline Chloride/Urea/ALCL3. Environ. Pollut. 20143 (4). DOI: $10.5539 /$ ep.v3n4p59.

(19) Bernasconi, R.; Magagnin, L. Electrodeposition of Nickel from DES on Aluminium for Corrosion Protection. Surf. Eng. 2017, 33 (2), $131-135$.

(20) Smith, E. L.; Fullarton, C.; Harris, R. C.; Saleem, S.; Abbott, A. P.; Ryder, K. S. Metal Finishing with Ionic Liquids: Scale-up and Pilot Plants from IONMET Consortium. Trans. Inst. Met. Finish. 2010, 88 (6), 285-291.

(21) Ferreira, E. S. C.; Pereira, C. M.; Silva, A. F. Electrochemical Studies of Metallic Chromium Electrodeposition from a Cr(III) Bath. J. Electroanal. Chem. 2013, 707, 52-58.

(22) Abbott, A. P.; Capper, G.; Davies, D. L.; Rasheed, R. K. Ionic Liquid Analogues Formed from Hydrated Metal Salts. Chem. - Eur. J. 2004, 10 (15), 3769-3774.

(23) Rahman, M. F.; Bernasconi, R.; Magagnin, L. Electrodeposition of Indium from a Deep Eutectic Solvent. J. Optoelectron. Adv. Mater. 2015, 17 (1-2), 122-126.

(24) Bernasconi, R.; Lucotti, A.; Nobili, L.; Magagnin, L. Ruthenium Electrodeposition from Deep Eutectic Solvents. J. Electrochem. Soc. 2018, 165 (13), D620-D627.

(25) Abbott, A. P.; Barron, J. C.; Ryder, K. S. Electrolytic Deposition of $\mathrm{Zn}$ Coatings from Ionic Liquids Based on Choline Chloride. Trans. Inst. Met. Finish. 2009, 87 (4), 201-207.

(26) Whitehead, A. H.; Pölzler, M.; Gollas, B. Zinc Electrodeposition from a Deep Eutectic System Containing Choline Chloride and Ethylene Glycol. J. Electrochem. Soc. 2010, 157 (6), D328.

(27) Abbott, A. P.; Barron, J. C.; Frisch, G.; Ryder, K. S.; Silva, A. F. The Effect of Additives on Zinc Electrodeposition from Deep Eutectic Solvents. Electrochim. Acta 2011, 56 (14), 5272-5279.

(28) Vieira, L.; Whitehead, A. H.; Gollas, B. Mechanistic Studies of Zinc Electrodeposition from Deep Eutectic Electrolytes. J. Electrochem. Soc. 2014, 161 (1), D7-D13.

(29) Yang, H.; Reddy, R. G. Electrochemical Deposition of Zinc from Zinc Oxide in 2:1 Urea/Choline Chloride Ionic Liquid. Electrochim. Acta 2014, 147, 513-519.

(30) Starykevich, M.; Salak, A. N.; Ivanou, D. K.; Lisenkov, A. D.; Zheludkevich, M. L.; Ferreira, M. G. S. Electrochemical Deposition of Zinc from Deep Eutectic Solvent on Barrier Alumina Layers. Electrochim. Acta 2015, 170, 284-291.

(31) Ibrahim, S.; Bakkar, A.; Ahmed, E.; Selim, A. Effect of Additives and Current Mode on Zinc Electrodeposition from Deep Eutectic Ionic Liquids. Electrochim. Acta 2016, 191, 724-732.

(32) Abbott, A. P.; Capper, G.; McKenzie, K. J.; Ryder, K. S. Electrodeposition of Zinc-Tin Alloys from Deep Eutectic Solvents Based on Choline Chloride. J. Electroanal. Chem. 2007, 599 (2), 288294.

(33) Pereira, N. M.; Salomé, S.; Pereira, C. M.; Silva, A. F. Zn-Sn Electrodeposition from Deep Eutectic Solvents Containing EDTA, HEDTA, and Idranal VII. J. Appl. Electrochem. 2012, 42 (8), 561571.

(34) Xie, X.; Zou, X.; Lu, X.; Xu, Q.; Lu, C.; Chen, C.; Zhou, Z. Electrodeposition Behavior and Characterization of Copper-Zinc 
Alloy in Deep Eutectic Solvent. J. Appl. Electrochem. 2017, 47 (6), 679-689.

(35) Xie, X.; Zou, X.; Lu, X.; Lu, C.; Cheng, H.; Xu, Q.; Zhou, Z. Electrodeposition of $\mathrm{Zn}$ and $\mathrm{Cu}-\mathrm{Zn}$ Alloy from $\mathrm{ZnO} / \mathrm{CuO}$ Precursors in Deep Eutectic Solvent. Appl. Surf. Sci. 2016, 385, 481-489.

(36) Fashu, S.; Gu, C. D.; Zhang, J. L.; Zheng, H.; Wang, X. L.; Tu, J. P. Electrodeposition, Morphology, Composition, and Corrosion Performance of Zn-Mn Coatings from a Deep Eutectic Solvent. J. Mater. Eng. Perform. 2015, 24 (1), 434-444.

(37) Bučko, M.; Culliton, D.; Betts, A. J.; Bajat, J. B. The Electrochemical Deposition of $\mathrm{Zn}-\mathrm{Mn}$ Coating from Choline Chloride-Urea Deep Eutectic Solvent. Trans. Inst. Met. Finish. 2017, 95 (1), 60-64.

(38) Maniam, K. K.; Paul, S. Progress in Electrodeposition of Zinc and Zinc Nickel Alloys Using Ionic Liquids. Appl. Sci. 2020, 10 (15), 5321.

(39) Badea, M. L. M.; Cojocaru, A.; Anicai, L. Electrode Processes in Ionic Liquid Solvents as Mixtures of Choline Chloride with Urea, Ethylene Glycol or Malonic Acid. UPB Sci. Bull. Ser. B 2014, 76 (3), $21-32$.

(40) Gabe, D. R. The Role of Hydrogen in Metal Electrodeposition Processes. J. Appl. Electrochem. 1997, 27 (8), 908-915.

(41) Carr, M. J.; Robinson, M. J. The Effects of Zinc Alloy Electroplating on the Hydrogen Embrittlement of High Strength Steels. Trans. Inst. Met. Finish. 1995, 73 (2), 58-64.

(42) Sriraman, K. R.; Brahimi, S.; Szpunar, J. A.; Yue, S. Hydrogen Embrittlement of $\mathrm{Zn}$-, Zn-Ni-, and Cd-Coated High Strength Steel. J. Appl. Electrochem. 2013, 43 (4), 441-451.

(43) Shamsuri, A. A.; Abdullah, D. K. Ionic Liquids: Preparations and Limitations. Makara J. Sci. 2011, 14, 101-106.

(44) Panzeri, G.; Tresoldi, M.; Nobili, L.; Magagnin, L. Electrodeposition of $\mathrm{ZnNi}$ Alloys from Ethylene Glycol/Choline Chloride Based Ionic Liquid. ECS Trans. 2016, 75 (15), 627.

(45) Wu, M.; Nguyen, H. P.; Vullers, R. J. M.; Vereecken, P. M.; Binnemans, K.; Fransaer, J. Electrodeposition of Bismuth Telluride Thermoelectric Films from Chloride-Free Ethylene Glycol Solutions. J. Electrochem. Soc. 2013, 160 (4), D196-D201.

(46) Wu, M.; Binnemans, K.; Fransaer, J. Electrodeposition of Antimony from Chloride-Free Ethylene Glycol Solutions and Fabrication of Thermoelectric Bi2Te3/(Bi1-XSbx)2Te3Multilayers Using Pulsed Potential Electrodeposition. Electrochim. Acta 2014, 147, 451-459.

(47) Panzeri, G.; Muller, D.; Accogli, A.; Gibertini, E.; Mauri, E.; Rossi, F.; Nobili, L.; Magagnin, L. Zinc Electrodeposition from a Chloride-Free Non-Aqueous Solution Based on Ethylene Glycol and Acetate Salts. Electrochim. Acta 2019, 296, 465-472.

(48) Panzeri, G.; Accogli, A.; Gibertini, E.; Varotto, S.; Rinaldi, C.; Nobili, L.; Magagnin, L. Electrodeposition of Cobalt Thin Films and Nanowires from Ethylene Glycol-Based Solution. Electrochem. Commun. 2019, 103, 31-36.

(49) Vorobyova, T. N.; Vrublevskaya, O. N. Electrochemical Deposition of Gold-Tin Alloy from Ethylene Glycol Electrolyte. Surf. Coat. Technol. 2010, 204 (8), 1314-1318.

(50) Maltanava, H. M.; Vorobyova, T. N.; Vrublevskaya, O. N. Electrodeposition of Tin Coatings from Ethylene Glycol and Propylene Glycol Electrolytes. Surf. Coat. Technol. 2014, 254, 388397.

(51) Pallaro, M.; Moretto, F. L.; Panzeri, G.; Magagnin, L. Sn-Cu Codeposition from a Non-Aqueous Solution Based on Ethylene Glycol for Wafer-Bonding Applications: Direct and Pulse Electroplating. Trans. Inst. Met. Finish. 2018, 96 (5), 265-268.

(52) Neuróhr, K.; Pogány, L.; Tóth, B. G.; Révész, Á.; Bakonyi, I.; Péter, L. Electrodeposition of Ni from Various Non-Aqueous Media: The Case of Alcoholic Solutions. J. Electrochem. Soc. 2015, 162 (7), D256-D264.

(53) Panzeri, G.; Accogli, A.; Gibertini, E.; Rinaldi, C.; Nobili, L.; Magagnin, L. Electrodeposition of High-Purity Nanostructured Iron Films from $\mathrm{Fe}(\mathrm{II})$ and $\mathrm{Fe}(\mathrm{III})$ Non-Aqueous Solutions Based on Ethylene Glycol. Electrochim. Acta 2018, 271, 576-581.
(54) Panzeri, G.; Tresoldi, M.; Rinaldi, C.; Magagnin, L. Electrodeposition of Magnetic SmCo Films from Deep Eutectic Solvents and Choline Chloride-Ethylene Glycol Mixtures. J. Electrochem. Soc. 2017, 164 (13), D930-D933.

(55) Lukaczynska, M.; Mernissi Cherigui, E. A.; Ceglia, A.; Van Den Bergh, K.; De Strycker, J.; Terryn, H.; Ustarroz, J. Influence of Water Content and Applied Potential on the Electrodeposition of $\mathrm{Ni}$ Coatings from Deep Eutectic Solvents. Electrochim. Acta 2019, 319, 690-704.

(56) Valverde, P. E.; Green, T. A.; Roy, S. Effect of Water on the Electrodeposition of Copper from a Deep Eutectic Solvent. J. Appl. Electrochem. 2020, 50 (6), 699-712.

(57) Du, C.; Zhao, B.; Chen, X. B.; Birbilis, N.; Yang, H. Effect of Water Presence on Choline Chloride-2urea Ionic Liquid and Coating Platings from the Hydrated Ionic Liquid. Sci. Rep. 2016, 6 (July), 114.

(58) Troter, D. Z.; Todorović, Z. B.; Đokić-Stojanović, D. R.; Đorđević, B. S.; Todorović, V.; Konstantinović, S. S.; Veljković, V. B. The Physicochemical and Thermodynamic Properties of the Choline Chloride-Based Deep Eutectic Solvents. J. Serb. Chem. Soc. 2017, 82 (9), 1039-1052.

(59) Abbott, A. P.; Harris, R. C.; Ryder, K. S. Application of Hole Theory to Define Ionic Liquids by Their Transport Properties. J. Phys. Chem. B 2007, 111 (18), 4910-4913.

(60) Reade, G.; Ottewill, G.; Walsh, F. Understanding Electrical and Electrolytic Conductivity. Trans. Inst. Met. Finish. 2000, 78 (2), 8992.

(61) Mahapatro, A.; Suggu, S. K. Modeling and Simulation of Electrodeposition: Effect of Electrolyte Current Density and Conductivity on Electroplating Thickness. Adv. Mater. Sci. 2018, 3 (2), 1.

(62) Giap, S. G. E. The Hidden Property of Arrhenius-Type Relationship: Viscosity as a Function of Temperature. J. Phys. Sci. 2010, 21 (1), 29-39.

(63) Knetsch, D.; Groeneveld, W. L. Alcohol as Ligands. III. Complexes of Ethylene Glycol with Some Divalent Metal Halides. Inorg. Chim. Acta 1973, 7, 81-87.

(64) Ruttink, P. J. A.; Dekker, L. J. M.; Luider, T. M.; Burgers, P. C. Complexation of Divalent Metal Ions with Diols in the Presence of Anion Auxiliary Ligands: Zinc-induced Oxidation of Ethylene Glycol to Glycolaldehyde by Consecutive Hydride Ion and Proton Shifts. J. Mass Spectrom. 2012, 47 (7), 869-874.

(65) Alesary, H. F.; Cihangir, S.; Ballantyne, A. D.; Harris, R. C.; Weston, D. P.; Abbott, A. P.; Ryder, K. S. Influence of Additives on the Electrodeposition of Zinc from a Deep Eutectic Solvent. Electrochim. Acta 2019, 304, 118-130.

(66) Pereira, N. M.; Pereira, C. M.; Araujo, J. P.; Silva, A. F. Zinc Electrodeposition from Deep Eutectic Solvent Containing Organic Additives. J. Electroanal. Chem. 2017, 801, 545-551.

(67) Rodriguez-Torres, I.; Valentin, G.; Lapicque, F. Electrodeposition of Zinc-Nickel Alloys from Ammonia-Containing Baths. J. Appl. Electrochem. 1999, 29 (9), 1035-1044.

(68) Harris, T. M.; Clair, J. S. Testing the Role of Metal Hydrolysis in the Anomalous Electrodeposition of Ni-Fe Alloys. J. Electrochem. Soc. 1996, 143 (12), 3918.

(69) Okamoto, H. Ni-Zn (Nickel-Zinc). J. Phase Equilib. Diffus. 2013, 34 (2), 153.

(70) Magagnin, L.; Nobili, L.; Cavallotti, P. L. Metastable ZincNickel Alloys Deposited from an Alkaline Electrolyte. J. Alloys Compd. 2014, 615, S444-S447.

(71) Ieffa, S.; Bernasconi, R.; Nobili, L.; Cavallotti, P. L.; Magagnin, L. Direct and Pulse Plating of Metastable $\mathrm{Zn}-\mathrm{Ni}$ Alloys. Trans. Inst. Met. Finish. 2014, 92 (6), 321-324.

(72) Povetkin, V. V.; Devyatkova, O. V. Formation of Metastable Phases in the Process of Electrodeposition of Metals and Alloys. Trans. Inst. Met. Finish. 1996, 74 (5), 177-178.

(73) Fayomi, O. S. An Investigation of the Properties of $\mathrm{Zn}$ Coated Mild Steel. Int. J. Electrochem. Sci. 2012, 7, 6555-6570. 
(74) Hammami, O.; Dhouibi, L.; Triki, E. Influence of Zn-Ni Alloy Electrodeposition Techniques on the Coating Corrosion Behaviour in Chloride Solution. Surf. Coat. Technol. 2009, 203 (19), 2863-2870.

(75) Mosavat, S. H.; Shariat, M. H.; Bahrololoom, M. E. Study of Corrosion Performance of Electrodeposited Nanocrystalline $\mathrm{Zn}-\mathrm{Ni}$ Alloy Coatings. Corros. Sci. 2012, 59, 81-87.

(76) Sriraman, K. R.; Brahimi, S.; Szpunar, J. A.; Osborne, J. H.; Yue, S. Characterization of Corrosion Resistance of Electrodeposited ZnNi Zn and Cd Coatings. Electrochim. Acta 2013, 105, 314-323.

(77) Tafreshi, M.; Allahkaram, S. R.; Farhangi, H. Comparative Study on Structure, Corrosion Properties and Tribological Behavior of Pure $\mathrm{Zn}$ and Different $\mathrm{Zn}-\mathrm{Ni}$ Alloy Coatings. Mater. Chem. Phys. 2016, 183, 263-272.

(78) Rashmi, S.; Elias, L.; Hegde, A. C. Multilayered Zn-Ni Alloy Coatings for Better Corrosion Protection of Mild Steel. Eng. Sci. Technol. an Int. J. 2017, 20 (3), 1227-1232. 